\title{
Review of Ultimate Strength Assessment of Ageing and Damaged Ship Structures
}

\author{
M. Tekgoz ${ }^{1} \cdot$ Y. Garbatov ${ }^{1} \cdot$ C. Guedes Soares ${ }^{1}$
}

Received: 2 July 2020 / Accepted: 25 September 2020 / Published online: 20 November 2020

(C) The Author(s) 2020

\begin{abstract}
The objective of this work is to provide an overview of the ultimate strength assessment of ageing and damaged ship structures in the last decades. Particular attention is paid to the ultimate strength of plates, stiffened panels, box girders, and entire ship hull structures subjected to corrosion degradation, fatigue cracking, and mechanical damage caused by accidental loading or impact. A discussion on the effect of the cyclic load on the plate rigidity, re-yielding, and ultimate load capacity on the ship hull girder is also part of the present study. Finally, some conclusions and discussions about potential future work are provided, identifying that more studies about the impact of corrosion degradation on the structural behaviour of the stiffened panels and the overall hull girders are needed. Studies related to the dynamic collapse behaviour of corroded and damaged ship structures under time-variant load also requires additional attention.
\end{abstract}

Keywords Marine corrosion $\cdot$ Damage $\cdot$ Ultimate strength $\cdot$ Finite element method

\section{Introduction}

Ship structures are most commonly made of steel, which renders them vulnerable to the corrosive environment leading to thickness loss and/or pitting over the years. In addition to the thickness loss due to the corrosion, the ship structures may experience structural damages throughout the service life

\section{Article Highlights}

- An overview of the ultimate strength assessment of ageing and damaged ship structures performed in the last decades is presented.

- Attention is paid to the ultimate strength of plates, stiffened panels, box girders, and entire ship hull structures subjected to corrosion degradation, fatigue cracking, and mechanical damage caused by accidental loading or impact.

- The impact of the cyclic load on the plate rigidity, re-yielding, and ultimate load capacity on the ship hull girder is also discussed.

- Conclusions about potential future work are provided, identifying that more studies about the impact of corrosion degradation and the dynamic collapse of corroded and damaged ship structures under time-variant load require additional attention.

Y. Garbatov

yordan.garbatov@tecnico.ulisboa.pt

1 Centre for Marine Technology and Ocean Engineering (CENTEC), Instituto Superior Técnico, Universidade de Lisboa, Av. Rovisco Pais, 1049-001 Lisbon, Portugal ranging from the ship to ship collision or grounding related damages (Liu et al. 2018a, b) to the ship motion-related cracks or mishandled cargo operations. The ageing-related thickness losses and structural damages may lead to the load capacity reduction, structural integrity breaches, and the potential increase in the working load acting on the ships.

There are several examples of ship structures that are thought to be structurally deficient, which resulted in sinking during heavy weather, causing environmental damages, namely, the single-hulled oil tankers, M/V Erika in 1999, and M/V Prestige in 2002 (Höfer 2003). The event of the Prestige, in particular, took long-term damage to recover due to the sheer size of the oil spill, 77000 tons of heavy fuel oil having a characteristic of high viscosity. These unfortunate instances brought about new regulations to be enforced as stipulated by the International Maritime Organization (IMO 2010) to better assess the residual ultimate load capacity of the damaged ship structures.

As with the intact ship structures, the ageing or damaged ship residual load capacity assessment has been a study of interest for the past decades to quantify the residual structural capacity and understand how the hull girders react to the external load exposure. These studies involve the stiffened plates or unstiffened ones that constitute the hull girder cross-section, the box girders, and the ship hull structures. The relevance of this subject is reflected in the specialist committees 
created by the Ship and Offshore Structures Congress to deal with these matters (Paik et al. 2006b; Wang et al. 2009a; Guedes Soares et al. 2009a; Czujko et al. 2012; Czujko et al. 2015; Czujko et al. 2018).

It is interesting to note that the progressive collapse characteristics of heavily corroded hulls are somewhat different from those of uncorroded hulls; the heavily corroded hull may reach the ultimate limit state by a buckling collapse of a compressed part even before a tensioned part yields while the intact hull usually reaches the ultimate limit state by tensile yielding of a tensioned part after a buckling collapse of the compressed part (Paik et al. 2003d).

The load carrying capacity of the hull girder is, in practice, estimated based on the assumption that the structure is allowed to follow a path under a pure-bending load with an incrementally increasing curvature with the static structural response. This assumption does not fully represent how the hull girder collapse occurs because hull girders during the seaway are under the alternate loading of the acting shear forces and bending moments. One force may dominate the other one in magnitude. Secondly, given the hostile sea environment that results in the hull girder to respond in a dynamic nature rather than a quasi-static one, the collapse pattern of the hull girder might be somewhat different from the one that collapses under the quasi-static load. Therefore, several studies are also reported here to understand the dynamic collapse of the hull girders.

\section{Corrosion Degradation}

Before assessing the strength of corroded ships and components, it is required to evaluate how corrosion progresses with time to predict the expected dimensions of the structures after exposure to corrosion for extended periods. For a long time, it was believed that corrosion had the sole effect of reducing steel thickness until it was shown that some mechanical properties also change with time, as described in the following sections.

\subsection{Modelling Corrosion Thickness Wastage}

Corrosion degradation of structures is one of the most severe problems in metal structures (see Figure 1). There are several environmental factors (Guedes Soares et al. 2009b; Guedes Soares et al. 2013) that cause the external steel plates to corrode, namely, the salty seawater, seawater temperature, $\mathrm{pH}$ and dissolved oxygen influence, sea flow, or ship routes. As for the internal plates, the degradation may be governed by the time in ballast, frequency of tank cleaning, temperature profiles, use of heating coils, humidity conditions, water and sludge accumulations, or microbial contaminations (Paik et al. 2003b).

The initial attempts to model the thickness reduction due to corrosion used a linear model of time, which would cover long periods of many years (Hart et al. 1986; Guedes Soares 1988; Shi 1993; Guedes Soares and Garbatov 1996a; Wirsching et al. 1998). As the importance of the phenomena increased, more data was collected, allowing more accurate models to be developed. On the one hand, experimental data on the corrosion of steel immersed in water was analysed and summarized by Melchers (2003a), concentrating on the details of the various mechanisms that were developed in the first 2 to 5 years of corrosion development. The other effort was made by classification societies analysing the large number of thickness measurements obtained in successive surveys (Yamamoto and Ikegami (1998); Wang et al. 2003). These efforts clarified that the thickness wastage was not developing linearly in particular in the initial years of their life. The difficulty of determining the characteristics of this early phase of corrosion development in ships was enhanced by the protective effect of coatings, which delay the initiation of corrosion and whose spatial pattern does not expose the full plates to the effect of corrosion in the initial phases. Despite this difficulty, the nonlinear character of corrosion development in the initial phases was established (Yamamoto and Ikegami 1998).

Several probabilistic corrosion wastage models containing the non-linear dependence on time have been proposed by Guedes Soares and Garbatov (1998a); Yamamoto and Ikegami (1998); Guedes Soares and Garbatov (1999b); Qin



Aft

Fore

Figure 1 Spatial distribution of corrosion thickness wastage on bulk carrier decks, 19th year (Garbatov and Guedes Soares, 2008) 
and Cui (2002); Ivanov et al. (2003); and Melchers (2003b); and models for specific ship types were proposed by Paik et al. (1998) and Paik et al. (2003a).

Guedes Soares and Garbatov (1998a, 1999b) developed a corrosion model to represent the non-linear time dependent corrosion wastage that is considered to be a good representation of the corrosion field based on the actual measured data as reported in TSCF (Tanker Structure Co-operative Forum 1992). The corrosion model includes a random initial time of no corrosion while the protection is active. After the failure of the protective coating, a non-linear time-dependent wastage increases up to a steady-state value. Cleaning the surface, or an involuntary action that removes that surface material originates the new start of the non-linear corrosion growth process.

The generic model of Guedes Soares and Garbatov (1998a, 1999b) has been validated with different data sets of corroded plate thickness measurements from various sources for tankers in (Garbatov et al. 2007; ABS 2002) and bulk carriers in (Garbatov and Guedes Soares 2008). This model has been compared with others, including the one proposed by Melchers (2003b), and was found that even in the early phases of corrosion development, the mean trend could be well reflected (Jiang and Guedes Soares 2008). Several studies have also been performed using the corrosion model fitted to the data of tankers and of bulk carriers as reported in Garbatov and Guedes Soares (2009a, 2010). Lampe and Hamann (2018) have proposed a method of Bayesian updating of a model by new measurements and demonstrated how it could be used by updating the model of Guedes Soares and Garbatov (1998a, 1999b) with new inspection data.

While the models described above deal with corrosion in plates a significant step forward was made when various types of corrosion were explicitly defined, and the areas where they apply were identified. As described in Zayed et al. (2007b, 2007a), different areas can be identified in ships, where different types of corrosion are developed, such as atmospheric corrosion (A in Figure 2), immersion corrosion ( $\mathrm{C}$ in Figure 2), alternating immersion and atmospheric (B in Figure 2), or inside tanks (D in Figure 2). These types of corrosion have different characteristics and different dependence on environmental parameters.

The corrosion model of Guedes Soares and Garbatov (1999b) has been extended to represent the various types of corrosion by representing the relevant environmental factors by the different environmental variables that affect each type of corrosion. It was found that there were different corrosion rates' initiation times for plates of ballast and cargo tanks and that the corrosion rates were different as well as the rate by which the corrosion rates decreased with time as described in the model for corrosion in tanks described in Guedes Soares et al. (2008a). For the corrosion in the marine atmosphere, it was found that it was influenced by various environmental


Figure 2 Locations for different type of environment affection the growth of corrosion (Zayed et al. 2007a)

factors (Southwell et al. 1979), including salinity, temperature, dissolved oxygen, $\mathrm{pH}$, and flow velocity, which were modelled by Guedes Soares et al. (2005). The influence of environmental parameters on corrosion under immersion conditions is modelled by Guedes Soares et al. (2013). It is important to realize that often ship plates are exposed to different environments in both faces (e.g. tanks and air or tanks and immersed in water) being exposed to two types of corrosion simultaneously and the total corrosion rate needs to account for both effects as described in Zayed et al. (2018).

These models can be used to determine the long-term effect of corrosion when ships are navigating and are exposed to different environmental conditions such as temperature, salinity, and liquid cargo inside the tanks, accounting for a fraction of time in each situation. The long-term effects are easier to model and to control if there are monitoring systems on-board that record the time spent in the various relevant conditions as discussed by Panayotova et al. (2004b, 2004a, 2008a, 2008b).

Gardiner and Melchers (2002) have pointed out that in bulk carriers, the plating that is in contact with coal will be subjected to rates of corrosion that are dependent on the type of coal. Hua and Cheng (2013) conducted a monitoring program by leaving steel test specimens within different types of coal, which allowed the understanding of the effect of different types of coal and demonstrated the usefulness of corrosion monitoring programs. Mohammadrahimi and Sayebani (2019) have conducted an analysis of a data set of thickness measurements in corroded areas of bulk carriers.

Finally, it must be pointed out that two main corrosion mechanisms are generally present in steel plates. One is a general wastage that is reflected in a generalized decrease of plate thickness. Another mechanism is pitting, which consists of very localized corrosion with very deep holes appearing in the plate that may subsequently lead to fatigue cracking.

Microbial corrosion is a special type that is not covered by the previous models as it induces very localized corrosion sometimes with very high corrosion rates and tends to occur 
in ballast tanks or other areas of ship structures with enclosed atmospheres and contact with water. A review of this type of corrosion is provided by Heyer et al. (2013).

\subsection{Mechanical Properties}

Most studies about the behaviour and strength of corroded structures have addressed the most visible effect of corrosion and have recalculated the strength of the corroded structures by considering a smaller thickness. However, changes in mechanical properties have been observed and quantified by several authors.

Sumi and co-workers (Sumi et al. (2006); Sumi (2008); Ahmmad and Sumi (2009); Islam and Sumi (2011)) have studied the behaviour of test specimens with pitting corrosion and concluded that both the ultimate strength and the deformability of these specimen were reduced due to the presence of pitting. Xu and Qiu (2013) showed changes in the mechanical, microstructural, and corrosion properties of stainless steel 316L under repeated repair welding. The specimen of the base metal and different conditions of shielded metal arc welding repairs were studied by looking in the microstructural changes, the chemical composition of the phases, the grain size (in the heat-affected zone), and the effect on the mechanical and corrosion properties. For artificial pitting corrosion, the tensile properties of steel material such as yield stress and elongation are affected by the shape, depth, and density of corrosion pits (Sheng and Xia, 2017). The results of tensile tests performed by Xu et al. (2016) also showed that the section loss due to pitting corrosion and uniform corrosion reduced the strength of the butt-welded joint specimens, while pits in the HAZ led to a significant decrease of ductility compared with the corroded base metal specimens with the same conditions.

A different line of work has been developed by Garbatov, Guedes Soares, and co-workers, who have started a study on the effect of corrosion on the ultimate strength of box girders and of stiffened panels by subjecting medium-size models of box girders to accelerated corrosion in seawater, as described in Domzalicki et al. (2009). After corrosion, these box girders have been tested up to ultimate strength as summarized in Saad-Eldeen et al. (2011a). The analysis of the experimental results leads to the conclusion that it was not enough to correct the thickness of the plates with general corrosion, but that there were changes in mechanical properties with the progress of corrosion which were influencing the results obtained in the experiments.

Several specimens have been cut from the box girders and subjected to mechanical tests, which showed that there was an important reduction of the mechanical properties as the modulus of elasticity and the yield and maximum tensile strength (Garbatov et al. 2014b). A similar effect has been observed in corroded specimens subjected to fatigue load (Garbatov et al. 2014a), where a significant reduction of fatigue strength from FAT 100 to $65 \mathrm{MPa}$ is identified, which was accompanied by a crack propagation starting from corrosion pits (see Figure 3 ).

To determine the influence of the surface condition and normal maintenance actions on ship hull, new test series have been conducted on sandblasted and sandpaper cleaned specimens (Garbatov et al. 2016a). An additional study was made to look at the effect of high-pressure-fresh-water-cleaning and corrosion cleaning by hammering on the mechanical properties of aged steel specimens (Garbatov et al. 2019).

Garbatov et al. (2019) analysed the mechanical properties of five groups of corroded specimens, in addition to the ones already analysed in the study reported in (Garbatov et al. 2016a), a total of 141 specimens, including non-cleaned, sand-blasted, sand-paper cleaned, high-pressure-fresh-watercleaning and cleaned by hammering specimens were experimentally analysed. The modulus of elasticity, yield stress, tensile strength, total uniform elongation, and their linear trend and associated uncertainties were analysed as a function of the degree of corrosion degradation and cleaning treatment procedure. It was observed a different degree of reduction of the Young modulus, total uniform elongation, and tensile strength and an enhancement in the case of the stresses at 0.2 .

The material property change may be caused by the corrosion degradation leading to surface roughness, stress concentration as a result of local corrosion pits, and cleaning treatment. The plate thickness and weight measurements for the specimens $\mathrm{B}, \mathrm{C}, \mathrm{H}$, and $\mathrm{W}$ were performed after cleaning the corrosion layer. Specimen A, which is corroded and non cleaned specimens, was subjected to corrosion degradation and a less degree of erosion since the open seawater was circulating the specimens involving some microorganisms, shells, and sand. Additional to this environment, specimens $\mathrm{B}$ and $\mathrm{C}$ were subjected to massive erosion during the blasting and paper cleaning (Garbatov et al. 2014b, 2016a), and specimen $\mathrm{W}$ were cleaned by high-pressure-fresh-water and specimen $\mathrm{H}$ were hammered, which distinguishes this treatment from others (see Figure 4).

(a)

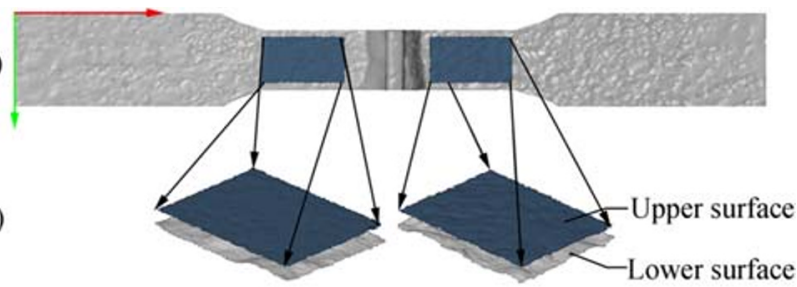

(c)



Figure 3 Corroded coupon (a), photogrammetry pit identification (b), and thickness visualization (c) (Garbatov et al. 2014a) 
Garbatov et al. (2019) recognized that the existence of a high degree of uncertainties in the measurement is due to corrosion degradation, erosion, heating, and induced residual stresses due to cleaning processes unavoidably also leads to uncertainties in the mechanical properties, estimated thickness and reference net-section used for the stress calculation and structural analysis. The breaking net section location of corroded specimens is not correlated with the locations of the minimum thickness, which leads to the conclusion that the minimum thickness is not the only parameter that governs the specimen failure and the distribution of the pits, shapes, how deep they are and the consequence singularities are very important in this respect.

Other independent studies have confirmed the degradation of mechanical properties of steel with increased corrosion levels. Qin et al. (2016) studied the degradation of mechanical properties of steel tensile test specimens subjected to neutral salt spray accelerated corrosion for different durations and then subjected to tensile tests. The level of corrosion was characterized by real surface topography, which identified the level of pitting corrosion. They concluded that after a certain threshold of corrosion, the yield strength, ultimate strength, and fracture strength would decrease significantly, and they developed equations to model that behaviour using modelling techniques described by $\mathrm{Hu}$ et al. (2015). Yang et al. (2016) have studied the corrosion of immersed steel plate elements in laboratory conditions, subject to a level of imposed stresses. They concluded that the different stress levels that the specimen are subjected to will change the time variation of corrosion as predicted by available models such as the one of Guedes Soares and Garbatov (1998a, 1999b).

Zhao et al. (2020) studied the tensile strength of Q345 steel with random pitting corrosion based on finite element (FE) analysis. They modelled the corrosion pits as a semi-ellipsoid, semi-sphere, cone, or cylinder shape, which were then



Figure 4 Stress-strain relationship of specimens A, B, C, H, and W (Garbatov et al. 2019) randomly distributed on the surface of the FE model of the specimen, and the accuracy of the FE model was validated by experimental results. They concluded that the tensile strength of steel with random pitting corrosion is closely related to corrosion depth and mass loss ratio.

The effect of pitting damage on the overall deformability and local ductile fracture initiation in tension test specimens of butt-welded joints, subjected to neutral salt spray corrosion, was investigated by Wang et al. (2018). The results showed that the total elongation of corroded welded joints shows a more significant linear decline trend than the ultimate strength.

Ma et al. (2019) studied the mechanical properties of highstrength steel under the action of pitting damage, and they observed that the yield strength and ultimate strength of the steel degrade as the pitting volume loss rate increases. They also concluded that cyclic loading can strengthen the cyclic stress and strain of the steel, but pitting damage leads to degradation of the cyclic stress and strain of the steel. Jia et al. (2019) studied the same steel. They concluded that "the influence of corrosion damage on the mechanical properties of steel is complex and cannot be characterized by section reduction alone. Both generalized elastic modulus and generalized yield strength decrease with corrosion damage. The cumulative fatigue damage makes the steel skeleton curves under cyclic loading and monotonic curves different. Cyclic loading increases the ultimate stress of steel at the expense of ultimate deformation ability".

Sheng and Xia (2017) have simulated corrosion pits mechanically in tension test specimens by mechanical drilling and milling conical blind holes. The effects of the shape, depth, and distribution of corrosion pits on the tensile properties of steel have been systematically investigated. Pit shape, depth, and distribution impacted little on the ultimate load of tensile samples; the ultimate strength almost correlated only with the maximum cross-sectional area. Yao et al. (2018) made experiments and numerical simulations to determine the material properties of the test specimen with pitting corrosion mechanically generated. They concluded that the modulus of elasticity, the yield and ultimate strengths, and the peak tensile strain would decrease approximately linearly with the degree of pitting (DOP). Yang et al. (2020) studied the behaviour of test specimens of high strength steel with one single mechanically generated pit. They concluded that there was a small effect of mechanically induced pits on the generalized elastic modulus of steel, but pitting had a substantial influence on the generalized yield strength and ultimate strength, which was very much correlated with the volume of material lost. So while corroded specimen exhibit changes that cannot be correlated only to changes of cross-sectional area or volume of material, the corroded steel specimen exhibit changes beyond those. 


\section{Ultimate Strength of Corroded Structures}

The ultimate strength of corroded plates has considered the main types of situation: plates with spread pit corrosion, with localized corrosion in some areas of the plate, eventually resulting from coalescing pits and generalized corrosion in the whole plate. A useful review has been published by Wang et al. (2014).

\subsection{Plates}

Generalized corrosion degradation on plates leads to both plane stiffness and load carrying capacity reduction (Guedes Soares 1988). Therefore, its influence has been studied over the years accounting for uniaxial load, edge shear and combined loading conditions, and tension loads accounting for general or localized corrosion states. These studies support the decision-making in the case of steel plating renewals, and, for example, similar guidance has been provided to evaluate the residual strength of the ship platings suffering from the localized pitting corrosion as reported by Daidola et al. (1997).

Numerous studies have been directed to quantify the load carrying capacity of locally corroded plates. For instance, Slater et al. (1999) studied the elastic buckling of plates with localized corrosion, accounting for the edge boundary conditions, corrosion locations, and corrosion pattern. They found that the corrosion leads to significant buckling strength loss in the plate. The spatial location of the corrosion patch has a significant effect on the buckling strength, and the localized corrosion in the middle of the plate and the corners leads to lower buckling strength than the one with a uniformly corroded plate due to the local plate buckling.

Sadovský and Drdácký (2001) also emphasized the influence on the plate buckling strength of localized corrosion. They concluded that localized corrosion might give rise to a greater scatter of buckling loads and that the corrosion effect in thin-walled structures is of importance and deserves attention.

Saad-Eldeen and Guedes Soares (2009) performed a series of non-linear finite element analysis to investigate the influence of the pitting corrosion on the load carrying capacity of rectangular plates by changing the plate geometry and pitting density distribution and proposed formulae based on the regression analysis to estimate load carrying capacity of the plates with pitting-related corrosion.

Pitted plates under biaxial loading were studied by Huang et al. (2010), who presented an empirical equation relating the ultimate strength reduction to the volume loss of material due to the pits. Jiang and Guedes Soares (2012) studied the influence of the partial depth pits under uniaxial loads accounting for the depth, location, and radius of the pits on plates of several slenderness using the finite element analysis. In the case of the pits on one side of the plate, it leads to a more pessimistic load capacity than the one that has pit corrosion on both sides. They concluded that the volume loss dominates the compressive capacity of pitted mild steel plates, while the plate slenderness ratio primarily governs the collapse behaviour of the plate itself. An empirical formula is also proposed to predict the ultimate load capacity of the plates under uniaxial load as a function of volume loss and plate slenderness (Jiang and Guedes Soares 2011). A closed-form formula was also presented to estimate the ultimate load carrying capacity of pitted mild steel plates under biaxial compression by Jiang and Guedes Soares (2012).

Silva et al. (2013) investigated the effect of pitted plates with random localized corrosion pits in rectangular plates under uniaxial loads. They considered two types of corrosion models, the non-uniform hexahedron corrosion and elliptical one drawing the attention to the shape of the corrosion state which is vital to the load carrying capacity assessment that may lead to local buckling or plasticity failure which is more influential than general thickness reduction. The corrosion model adopted was reported in Guedes Soares and Garbatov (1999b). They concluded that the proposed method with the Monte Carlo simulation for the indented localized corrosion wastage is an aggressive idealization that may provide an intelligent design life for the thin-walled structures and it is suitable for an extensive range of the corrosion type degradations. They also proposed an empirical formula to predict the strength reduction that accounts for the shape of the corroded surface, which shows a good agreement and accuracy.

Numerous studies have also been directed to quantify the load carrying capacity of locally corroded plates as reported by Ok et al. (2007); Khedmati et al. (2011); Zhang et al. (2017b), and Abdussamie et al. (2018).

Some have also been reported to evaluate the residual strength of the locally corroded plates under combined loading conditions. For instance, the load carrying capacity of the plate structural components with pit corrosion, modelled as circular cylinders, has been documented under uniaxial trust and edge shear by Paik et al. (2003b) and Paik et al. (2004), respectively. The nature of the corrosion is considered both uniformly and non-uniformly distributed. Interesting findings have demonstrated that the plate load capacity with pit corrosion is sensitive to the loading conditions where the smallest sectional area governs the mechanism in the case of the uniaxial trust. In contrast, it is governed by the degree of pitting in the case of the edge shear. They also proposed design formulas to estimate the extra strength of the plates with pit corrosion accounting for the uniaxial and edge shear loading conditions, which are suitable for both uniformly or nonuniformly distributed corrosion cases. They concluded that the load capacity of the plate with a pit or general corrosion leads to a significant reduction. A similar study has also been reported to quantify the residual capacity of the plates with 
pitting corrosion under combined loading conditions as reported by Islam and Sumi (2011) and Zhang et al. (2016).

Nakai et al. (2006) investigated the ultimate strength of the hold frames of aged bulk carriers with pitting corrosion. Nakai et al. (2006) analysed the ultimate strength of plates under combined in-plane compression and bending. In this study, the nature of corrosion is considered uniformly distributed. A general conclusion was drawn that the ultimate load carrying capacity of the plate is lower when considering the corrosion as evenly distributed with conical shape pits than those of uniformly corroded plates with average plate thickness loss of the whole plate. The reduction in the ultimate load capacity of the plate due to the pitting corrosion is almost independent of the stress gradients. They also drew the attention to find out which failure mode would be the most detrimentally affected by pitting corrosion; namely, tension load due to the bending and shear with the initiation of the crack in determining the load carrying capacity of the transverse frame webs.

Nakai et al. (2007) demonstrated a visual of pitting corrosion of hold frames of bulk carriers. They found that the nature of the corrosion is non-uniform and its shape is similar to the conical shape after observing from the surface and through the plate thickness. Based on these findings, they have performed a series of non-linear FE analysis to estimate the load carrying capacity of the plate element under combined loading conditions, namely, uniaxial thrust, biaxial thrust, and edge shear.

Due to the complexity in measurements of different structural imperfections, including corrosion degradation and initial distortions, the random field modelling (Teixeira and Guedes Soares (2008), Garbatov and Guedes Soares (2019), Woloszyk and Garbatov (2020)) provides a good way of stochastic modelling of corroded and deformed plate surfaces (see Figure 5).

The non-uniform spatial type of corrosion studies has also been reported, for instance, Teixeira and Guedes Soares (2008) studied the collapse strength of the steel plates accounting for the spatial distribution of corroded plate thickness representing the random fields which are defined based on the model proposed by Guedes Soares and Garbatov



(a) 3D view

(b) $2 \mathrm{D}$ view

Figure 5 Corroded plate surface (Garbatov and Guedes Soares, 2019). a $3 \mathrm{D}$ view, $\mathbf{b} 2 \mathrm{D}$ view (1999b). They demonstrated that the strength of the plate with a spatial distribution of corroded thickness represented by a random field is usually lower than the one obtained for uniform corrosion. Similar findings have also been reported by Mateus and Witz (1998).

Silva et al. (2013) performed a series of 570 non-linear finite element calculations to evaluate the load capacity of the non-uniformly corroded plates under uniaxial compressive load using the Monte Carlo simulations for the surface modelling allowing an adequate representation of the real corroded surface accounting for the random origin of the location and the form of the corrosion depths. The non-linear corrosion model as proposed by Guedes Soares and Garbatov (1999b) has been used, and the parameters defining this model has been documented by Garbatov et al. (2007) and Garbatov and Guedes Soares (2008). They concluded that for 30 years of service life without replacement of plate, the ultimate strength has been reduced from 0.69 to 0.44 representing a $37 \%$ reduction.

Rahbar-Ranji (2012) adopted the approach of describing the surface of corroded plates by random fields and then calculated the ultimate strength by a non-linear, large deflection finite element analysis.

Khedmati et al. (2015) developed an analytical method to determine the ultimate strength of plates randomly corroded in both sides by adopting an equivalent thickness of the corroded plate. Finite element calculations were also conducted using a distribution of random plate thickness to represent pitting in a way similar to the one of Silva et al. (2013, 2014), and they obtained good agreement between numerical and analytical approaches.

Another study on the effect of pitting corrosion is due to Wang et al. (2014). Piscopo and Scamardella (2018) conducted a parametric study to determine the effect of pitting corrosion on the ultimate strength of plates with different boundary conditions and welding-induced initial imperfections, comparing the results with existing design equations.

Feng et al. (2020) have conducted an experimental test program with plates with mechanical pits subjected to inplane compressive loads. A high density of pits was used with round and square shape and with different depth. The plates were of $145 \times 80 \times 1.5 \mathrm{~mm}$, thus with $\mathrm{a} / \mathrm{b}=1.8$, which is smaller than the typical value of 3 often found in ship structures. FE calculations were made for plates with a degree of pitting (DOP) ranging from 4 to $23 \%$, and the depth of pits ranged from 0.25 of the initial thickness to full thickness, obtaining good correlation with experiments. They concluded that the decrease of strength varies about linearly with the DOP, being more intense for low slenderness plates.

A less common type of structures is the web-core sandwich metal beams and plates, whose strength reduction due to corrosion has been studied by Jelovica et al. (2013), Jelovica et al. (2014). 


\subsection{Stiffened Panels}

Corrosion influence on the structural load capacity of the stiffened panel is similar to unstiffened plates. The stiffener plays an essential role in supporting the ship plating to withstand the external hull girder load. The corrosionrelated damages may lead to in-plane rigidity and load carrying capacity reduction of the stiffened panel components, stiffener detachment due to the grooving type of corrosion degradation around the welding beads and collapse behaviour changes, stiffener tripping due to low torsional rigidity having a significant impact on the overall hull girder load carrying capacity. Therefore, several studies have been performed in this regard.

Dunbar et al. (2004) studied the localized corrosion on the stiffened panel load capacity, accounting for the weldinginduced stresses where the corrosion is only considered on the plating. They demonstrated the importance of the corrosion location on the plating in terms of the load carrying capacity of the stiffened panel, indicating that the middle span corrosion is the most influential one.

Amlashi and Moan (2005) investigated the load capacity of the stiffened plates with localized pitting corrosion under biaxial compressive loading. Several conclusion was drawn that the pitting corrosion may lead to significant load carrying capacity reduction. The loading capacity under the biaxial load is effected by both the level of degree of pitting and also by the smallest sectional area.

Wang et al. (2015b) have studied the strength of stiffened panels with corrosion grooving damage along the welds of the stiffeners, and they concluded that the grooving depth has a more significant influence on ultimate strength degradation than corrosion width with the same volume loss. Additional studies on stiffened plates have been done by Sultana et al. (2015) and Zhang et al. (2017b).

Rahbar-Ranji (2015) demonstrated that when the column buckling is dominant in the intact stiffened panel, the influence of the corrosion on the buckling strength is not noticeable. However, when plate-web torsional buckling is a dominant mode, the reduction of the buckling strength is significant. A fascinating insight is given that corrosion concentrates at full length in mid-bay. The reduction of the elastic buckling is more pronounced than when corrosion occurs at the whole region of the plate and stiffener together showing the importance of the localized corrosion effect. Additional results can be found in Rahbar-Ranji (2015). The stiffened panel failure mode changes due to the non-uniform pitting are also observed in the study reported by Wang et al. (2018).

Shi et al. (2016) have conducted a finite element study of stiffened panels with pitting, which were used to define the experimental study conducted by Zhang et al. (2017a), while Shi et al. (2018) have compared the experimental results with numerical calculations, which showed good correlation.
Garbatov et al. (2016b) performed a series of experimental collapse tests on the severely corroded stiffened panels which were initially cut from a box girder that was corroded in real sea conditions and compared with a numerical solution in terms of the load carrying capacity demonstrating the fact that the corrosion degradation has a significant influence on the ultimate capacity reduction (see Figure 6). The numerical and experimental predictions show a good agreement. They concluded that the strength reduction might be affected by several reasons, namely, the degree of the degradation, pit density, boundary and initial imperfection states, type of the failure modes, and material property changes.

Woloszyk et al. (2018) performed a series of non-linear finite element analysis to estimate the load carrying capacity of the severely corroded stiffened panels, which were experimentally tested and reported by Garbatov et al. (2016b) and compared with the design formulas provided by the standard structural rules showing a good agreement. The corrosion in the numerical solution has been modelled with the equivalent thickness enabling a fast solution.

\subsection{Box Structures}

There is limited literature on the collapse behaviour of the corroded box girders. Several studies have been performed in (Saad-Eldeen et al. 2011a, b, 2012, 2013b, 2013a, Saad-



(a)



(b)

Figure 6 Post-collapse deformed stiffened plate (a) and thickness distribution (b) (Garbatov et al. 2016b) 
Eldeen et al. 2013c, Saad-Eldeen et al. 2014) where the impact of the corrosion on several parameters, namely, the bending rigidity reduction, ultimate load capacity reduction, failure modes of the corroded stiffened panels was analysed and interesting fact has been discovered that the corrosion may lead to the material property changes.

Saad-Eldeen et al. (2010) conducted an experimental test on a box girder that represents the midship section to obtain the behaviour, modes of failure, and load carrying capacity under a pure-bending moment. They conducted three loading cycles, where the first two were used to release the weldinginduced residual stresses, and the third one to estimate the ultimate strength where the energy dissipations are $36.16 \%$ and $17.25 \%$ for the first and second cycles, respectively, indicating the discharge of the welding-induced residual stresses (see Figure 7). Several failure modes were observed, such as tension field yielding, tripping of longitudinal stiffeners, and out-of-plane deformations of the plates. They compared the ultimate load capacity of the box girder obtained in the test with the empirical formulae showing a good agreement.

\subsection{Ship Structures}

The corrosion is of paramount importance for the ship structures because it leads to decrease in both the local and global load capacity of hull girder and to increase the working load acting on the hull girder and jeopardizes the structural integrity of the hull girder. According to IMO, the longitudinal strength of the ageing ship should not be less than $90 \%$ of the new build ship hull (Paik et al. 2003d).

Yamamoto and Yao (2001) studied the hull girder collapse strength under longitudinal bending, accounting for the corrosion degradation. They have confirmed that the transverse section modulus and ultimate load capacity reduce deterministically even if there is a random scatter in each structural component that a similar observation has also been made by Saad-Eldeen et al. (2013b).

The progressive collapse characteristics of heavily corroded hulls are somewhat different from those of uncorroded hulls; the heavily corroded hull may reach the ultimate limit state by buckling collapse of a compressed part even before a tensioned part yields, while the intact hull usually reaches the ultimate limit state by tensile yielding of a tensioned part after buckling collapse of the compressed part (Paik et al. 2003d). They concluded that the hull girder is moderately reduced by the corrosion effects when the average corrosion rate is considered. In contrast, the ultimate strength is decreased significantly with severe corrosion rates.

Several corrosion-related studies to estimate the hull girder collapse capacity have also been presented by Hu et al. (2004) and Kim et al. (2014), analysing different ship types.



(a)



(b)

Figure 7 Experimental set-up (a) and force displacement (b) (SaadEldeen et al. 2013c)

\section{Ultimate Strength of Damaged Structures}

\subsection{Damaged Plates}

Steel structures can usually suffer various types of damages while in service. Some types of damages, such as corrosion and fatigue cracking, are related to age. Still, others are more likely to be mechanical damage caused by accidental loading or impact (Paik et al. 2003c). Several studies have been directed in this regard to understand the residual structural capacity of the damaged plates better to help in the decision-making in terms of the steel renewal. Several causes that may lead to plate collapse are the mechanical damages or unexpected events during the cargo loading and unloading operations, ship collisions or ice loads, fatigue cracks that may lead to plate in-plane stiffness and load capacity reduction. 


\subsubsection{Influence of Dent-Related Damages}

Paik et al. (2003c) performed a series of non-linear finite element analysis to evaluate the loading capacity of the dented steel plates under uniaxial compressive loading accounting for the shape of the dent. They showed that the residual strength of the dented plate is not significant if the dent diameter is small regardless of the dent depth. However, the diameter of the dent damage is highly influential on the loading capacity along with its depth. The dent location is more influential when it approaches the unloaded edges than in the centre of the plate where they demonstrated that the reduction might lead to $20 \%$ in comparison with the dent in the centre of the plate. They proposed a closed-form formula to estimate the load carrying capacity of the dented plates based on the insights collected.

Luis et al. (2008) studied the influence of the dimple infections that may occur during the local accidents on the load carrying capacity of the plates accounting for the position of the dimple that the effect of the dimple imperfection is more significant when it gets closer to the unloaded edge. It was shown that when the global imperfection is asymmetrical, the dimple influence is more significant. They concluded that the plate slenderness and imperfection amplitude is an influential factor

Considering the effect of dent shape, size (depth, diameter), and location, Paik et al. (2003c) performed an ultimate strength analysis of simply supported steel plates under axial compression, leading to the derivation of a closed-form formula. Rectangular plates with dents were studied by Guedes Soares et al. (2008b) and Luis et al. (2008), considering different configurations of plates and different locations of the dents. Still, they were smaller than the ones studied in this paper, and therefore they had a smaller impact on the plate ultimate load. For thin square plates under uniaxial compression, Raviprakash et al. (2012) reported that the variation of the size and angle of the orientation for longer dents reduces drastically the ultimate strength. Also, the effect of dent parameters on ultimate strength is magnified with increasing the plate thickness.

In-service damages are also accumulated throughout a ship's life due to overloading or accidents and may change or even "shakedown" the production-related imperfections. One-sided residual deflections characterize these damages over adjacent panels accompanied by residual stresses (Paik et al. 2006a). Paik et al. (2009) reported several studies regarding the strength of dented plates and the residual stress pattern resulting from the damage, as the work is done in Nikolov $(2007,2008)$ who concluded that the anti-symmetric damage of adjacent plates is the most unfavourable shape of damage in terms of the ultimate strength and the amplitude of local damage is not as important to the plate's strength.
Paik et al. (2003c) studied the effects of shape, size (depth, diameter), and location of the dent on the ultimate strength of simply supported steel plates under axial thrust. It was concluded that the change of localized dent location in the longitudinal direction of the plate affects the ultimate strength. As the dent location becomes closer to the unloaded edges, the ultimate strength decreased by $20 \%$, compared with the central dent.

Luis et al. (2008) studied the ultimate strength of long plates with localized dents, while Guedes Soares et al. (2008b) have studied the effect of dent locations on the ultimate strength. They found that the effect of local imperfections depends on the shape and amplitude of the damage. They also found that the effect of the localized imperfection location is related to the size of the damaged area.

Raviprakash et al. (2012) explored the influence of various dent parameters (length, width, depth, and orientation) on the ultimate strength of thin square plates under uniaxial compressive loading. It was found that the longer dents with a variety of sizes and angles of orientation drastically reduce the ultimate strength. The effect of dent parameters magnifies with an increase in the plate thickness.

Saad-Eldeen et al. (2015a) compared the stress-strain behaviour of rectangular steel plates accounting for the presence of an opening or a dent when a uniaxial compressive load is applied. Extensive non-linear finite element analyses were performed, where the effect of several governing parameters of the stress-strain relationship was analysed. The similarity in the structural response of a plate with a dent or an opening is identified. The pre- and post-buckling behaviour, stress-strain relationship, ultimate strength, and lateral deformation were investigated (see Figure 8).

Saad-Eldeen et al. (2015b) performed a series of finite element analysing damaged steel plates with a local dent. Several parameters were considered (plate thickness, dent orientation, dent direction and dent size). It was concluded that the occurrence of dent damage in the opposite direction to the initial imperfection reduces the effect of a dent on the ultimate strength as the plate thickness increases. An inflexion point of the plate slenderness with and without dent was observed, at which the behaviour of the plate changed. A certain dent breadth to plate breadth ratio is established, revealing the different plate structural response. Based on the performed analyses, a generalized expression of the ultimate strength reduction factor due to dent damage was developed.

Several experimental studies have been reported for perforated plates subjected to compressive load by Kim et al. (2009) and Saad-Eldeen et al. (2019) and for the perforated plates with locked cracks by Saad-Eldeen et al. (2016) analysing the residual collapse behaviour of plates under uniaxial load (see Figure 9). 




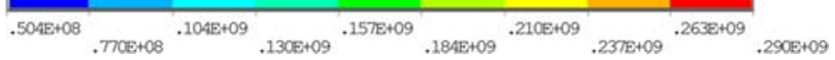

Figure 8 Stresses distribution, plate with central dent (Saad-Eldeen et al. 2015b)

\subsubsection{Impact of Crack-Related Damages}

The presence of the crack may also lead to a structural capacity reduction in ship plating; therefore, several studies have been oriented in this regard. Some studies have been presented to understand the behaviour of the elastic buckling strength and post-buckling strength of the cracked plate as reported by



(a)

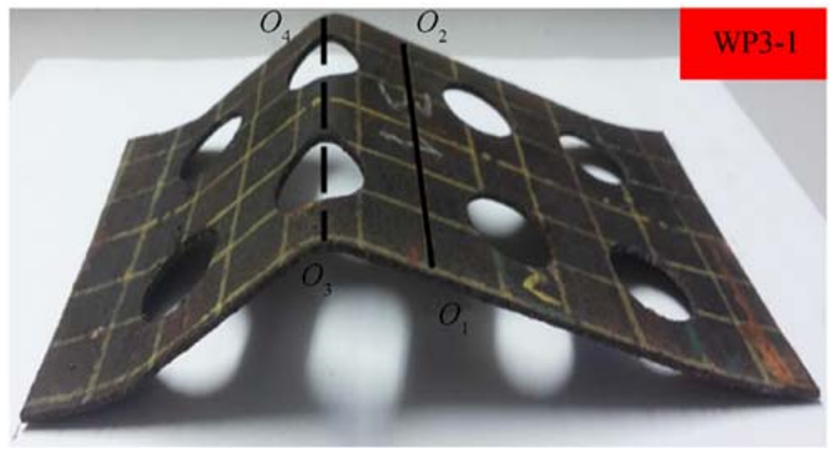

(b)

Figure 9 Post-collapse deformed shapes of specimen WP2-1 (a) and WP3-1 (b) (Saad-Eldeen et al. 2019)
Shaw and Huang (1990); Riks et al. (1992); Vafai et al. (2002); Brighenti (2005); Alinia et al. (2007a); Alinia et al. (2007b), and Khedmati et al. (2009).

Paik et al. (2005) studied the influence of the transverse locked crack presence on the plates under uniaxial compressive and tension load on the load carrying capacity experimentally and numerically where it was demonstrated that the fatigue cracking damage reduces the ultimate strength of a steel plate significantly. It was shown that when the crack approaches the unloaded edges, it leads to a significant capacity reduction in the plate. It was shown that as the crack size increases, it gives rise to load capacity reduction. The longitudinal crack influence on the plate strength under uniaxial compressive load has also been reported in Paik (2008).

Wang et al. (2009a) investigated the influence of the multiple cracks on the ultimate load carrying capacity of the structural members where they concluded that the existence of the small disturbing cracks reduces the load capacity compared to a single cracked plate.

Bayatfar et al. (2011) studied the influence of the transverse cracks on the ultimate strength of a steel plate under uniaxial compression, accounting for the crack length and locations. They concluded that the most prominent crack location is the ones in the unloaded edges of the plates. The influence of the crack damage on the plate load carrying capacity accounting for its length, direction, and inclination has been presented in Cui et al. (2016).

\subsection{Damaged Stiffened Panels}

In the case of stiffened panels, Witkowska and Guedes Soares (2008) investigated numerically the structural behaviour and ultimate strength of damaged stiffened panels by a dent that could be caused by a fall or strike of an object. It has been found that stiffened panels present quite good performance while subjected to the local damage; however, depending on geometrical characteristics, the stiffener deformations may significantly reduce the ultimate strength. A follow-up work was reported by Witkowska and Guedes Soares (2015).

The effect of local damage in a stiffener, modelled as local imperfection, on the ultimate strength of stiffened plates has been studied by Witkowska and Guedes Soares (2009). Several parameters related to the dent location, size and number of dents were considered. It has been found that the local damage on the stiffener can change the collapse mode of the plate and decrease its ultimate strength. The strength reduction depends on the location of the dent as well as the initial global deflection. For more than one damage location, the collapse of the plate follows the pattern induced by the damage in a more dominant position, and the other damage only decreases the value of strength. The dent-related damages have also been studied by Xu and Guedes Soares $(2013,2015)$ for narrow and wide stiffened panels under uniaxial compression. 
Experimental work on very small scale specimens were used to study the effect of dents in stiffened plates located in the plate fields (Amante et al. 2015) or damaging the stiffeners (Chujutalli et al. 2020). The experimental work agreed very well with finite element calculations, which proved once more to be a reliable method to predict the ultimate strength of these damaged structures.

For cracked stiffened panels, Paik and Kumar (2006b) investigated numerically the ultimate strength of a longitudinally stiffened panel with cracks subjected to axial compressive or tensile loads. It was concluded that the crack significantly reduces the ultimate strength of the stiffened panel as the outof-plane deformation increases.

Regarding the ultimate strength of cracked stiffened plates, Margaritis and Toulios (2012) concluded that if the crack faces came into contact, and depending on the aspect ratio and crack length, the structural stiffness may slow down, or even temporarily reverse the rate of collapse, or results in a small increase of the ultimate strength. Also, the failure mode may depend on the crack length.

Bayatfar et al. (2014) analysed the influence of crack lengths and locations on the ultimate compressive strength of imperfect unstiffened and stiffened plate elements. It was observed that the effect of crack on reducing the ultimate strength is increasing as the crack is located near the crest of the initial imperfection, rather than the location with zero imperfection.

Xu et al. (2014) analysed the ultimate residual strength of stiffened panels numerically with locked cracks under axial compressive loading. The influence of various geometrical characteristics of cracks and panels was investigated. It was concluded that the effect of the crack length on the ultimate residual strength depends on the crack orientation, where a slight effect occurs for longitudinally oriented crack and a significant one for the transversely oriented crack.

Some studies have been directed to the impact of the existing cracks on the ultimate load carrying capacity of the plates accounting for the edge shear loading as reported in Wang et al. (2015a, b), drawing the attention to the shear strength of the damaged structural components and the other studies accounting for the uniaxial compressive load as presented by Xu et al. (2014) where the influence of the stress field created by the crack and its size and orientation influence on the ultimate strength capacity reduction and collapse shape has been emphasized (see Figure 10).

Shi et al. (2017) have reported an experimental study on the ultimate strength of stiffened panels with a crack with different orientations relative to the loading. The degrading effects of the crack on the strength were discussed, and Shi et al. (2019) have conducted finite element calculations that were validated with the experiments and are thus available to study different other cases.

Cui and Wang (2020) have studied the strength of pitted stiffened plate with a circular opening. They performed experiments on a three-bay stiffened panel with a circular hole

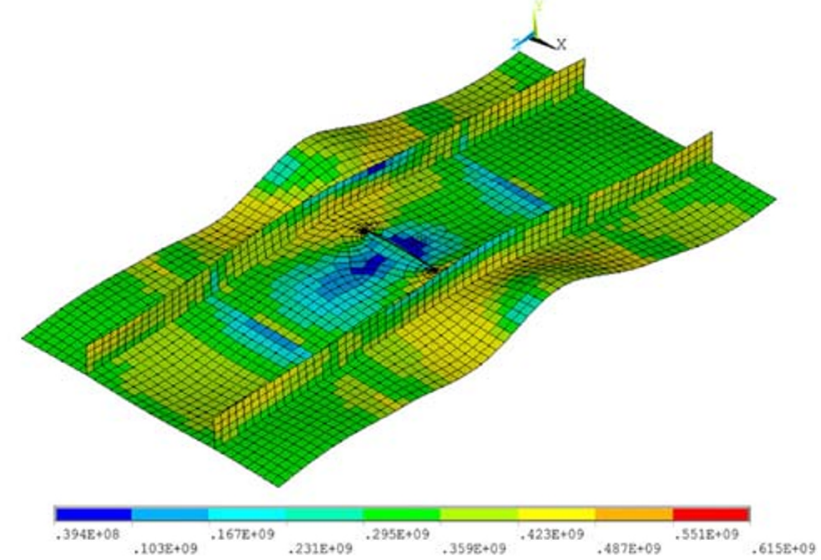

(a)

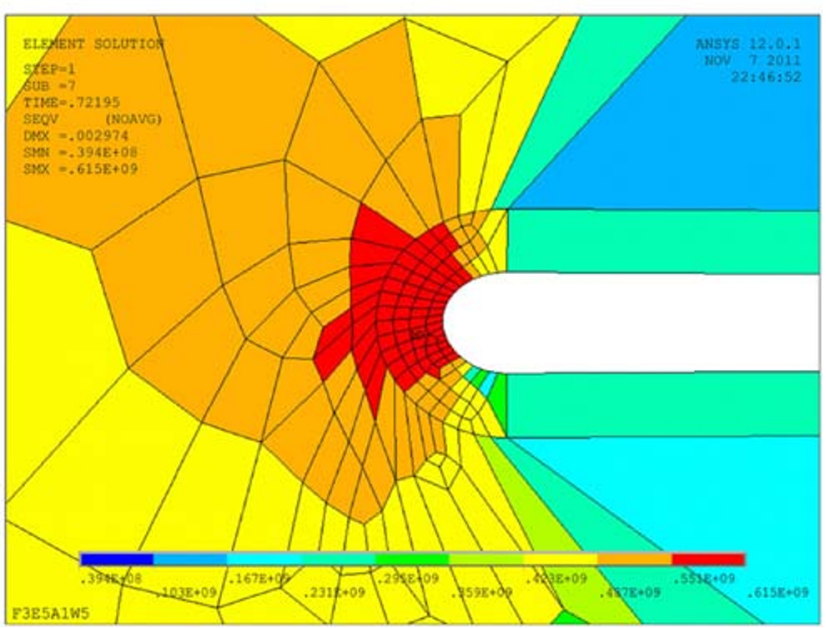

(b)

Figure 10 Stress distributions at ultimate limit state for cracked panel (a) and local crack stress distribution (b) (Xu et al. 2014)

covering a large part of the width of the central plate. Mechanically generated pits perforating the plate were considered in all plate elements in different number and location. They concluded that even for the same volume of corrosion, the ultimate strength may deviate significantly depending on the corrosion level and the extend of the opening.

\subsection{Damaged Box Structures}

Box girders are built to represent, in a way the behaviour of the hull girder in terms of the load carrying capacity. The collision or grounding-related damages or fatigue-related cracks may lead to consider the load carrying capacity of the hull girder. Therefore, some studies have been presented in this field.

Lee et al. (2008) performed ultimate and residual strength tests on five box girder models, four of which have ellipseshaped damage, which represents the shape of the bulbous bow of colliding ships. 
For large scale structural components as box girders, Shi and Wang (2012) explored the ultimate strength of an intact open box girder with cracks, subjected to different loading conditions, as a function of crack length and locations. It was concluded that the box girders with a crack located at the edge show the biggest reduction of the ultimate strength in torsion, compression, and bending loads.

The fatigue-related crack influence under torsional loading has been reported in Shi and Wang (2012) where they demonstrated that the size of the crack has a significant influence on the load carrying capacity of the box girder and the edge crack is the most influential one in terms of the load carrying capacity. Collison or grounding-related box girder damage case study has been reported in Benson et al. (2013) by drawing the attention to the damage-related residual stress, which increases the damage by $10 \%$.

Yamada and Takami (2015) presented an experimental collapse test on a damaged box girder assuming a ship-to-ship collision to understand the collapse behaviour of damaged hull girders under quasi-static load. The numerical and analytical solutions have validated the results. During the experiment, three collapse behaviours, namely, panel buckling, stiffener tripping, and the overall collapse of the stiffened panel, have been registered. Due to the asymmetry, which leads to the neutral axis rotation, one side of the damaged side shell was observed under only a compressive load. The load capacity of the numerical solution is in good agreement with the experiment.

\subsection{Damaged Ship Structures}

Ship structural integrity is of great importance at sea. One of the main concerns of ship designers, shipbuilders, and ship owners is the safety of the ship at sea. The structural damage studies, apart from the corrosion-related one, are concentrated on either fatigue-related cracks due to the ship cyclic motions or ship collisions and grounding damages.

Ship collisions and grounding may also lead to catastrophic ship and environmental damages. The strength analysis needs to account for the ultimate capacity of the hull girder, including permanent deformation and post-buckling behaviour. Real foreseeable scenarios shall be investigated in this regard as far as is reasonably practicable (IMO 2010).

When the ship collision or grounding-related damage occurs, possible consequences from a structural strength point of view includes reductions in stiffness and strength of shell and deck panels under subsequent lateral loads or in-plane loads, namely, the longitudinal bending, which results in the decrease in the ultimate hull girder bending strength (Smith and Dow 1981).

Gordo and Guedes Soares (2000) predicted several damaged hull girder residual capacities using the Smith method, a progressive collapse method. They concluded that in the case of the grounding, the ship hogging bending moment is more affected by the bottom damage. They suggested that in the case of the ship grounding, it is better to keep the ship in sagging condition. They draw attention to the significant damage reduction in the design stage when it comes to container ships.

Some authors drew attention to the residual prediction methods of the simplified methods. For example, Mansour et al. (2003) investigated the residual strength of a single hull tanker after grounding. The ultimate load capacity assessment was carried out using the assumed bending stress distribution method as proposed by Paik and Mansour (1995) and the one as suggested by Rutherford and Caldwell (1990). The residual strength index, as defined based on the sectional modulus and based on the ultimate strength capacity, was compared. They concluded that the residual strength index definition based on the ultimate strength is a better representation of the residual capacity of the hull girder. Guedes Soares et al. (2008b) reported the results of a benchmark study in which several approximate methods were used to predict the ultimate strength of a damaged ship hull, demonstrating the usefulness of this type of methods.

Wang et al. (2009b) demonstrated that in the case of the grounding, the initial yield or linear sectional modulus methods predict the upper (sagging bending moment) and lower (Hogging bending moment) bound of the residual strength concerning the ones predicted by the progressive collapse analysis. In the case of the collision, sectional modulus methods predict the upper (hogging bending moment) and lower (sagging bending moment) bound of the residual strength to the ones predicted by the progressive collapse analysis. Therefore, if one would like to have a conservative prediction in the case of the ship grounding, the proper choice would be the residual hogging bending moment with the sectional modulus method. In the case of the ship collision, the appropriate option might be the residual sagging bending moment with the sectional modulus method.

Several structural reliability-based studies have also been reported in analysing the residual strength of damaged ship hull girders using the Smith's method (Jia and Moan 2008; Hussein and Guedes Soares 2009; Luis et al. 2009).

Reliability-based studies have also been published considering the effect of corrosion or corrosion and fatigue on the ultimate hull strength (Guedes Soares and Garbatov (1996b, 1997, 1998b, 1999a); Akpan et al. (2002); Hu et al. (2004); Sun and Guedes Soares (2006); Guo et al. (2008); Wang et al. (2008); Garbatov and Guedes Soares (2009b, 2011); Guo et al. (2012); Parunov et al. (2013); Zayed et al. (2013); Huang et al. (2014); Dong and Frangopol (2015); Campanile et al. (2016); Garbatov (2016); Garbatov and Guedes Soares (2016, 2017); Corak and Parunov (2019); Woloszyk and Garbatov (2019)).

When the structural damages occur in the ship, the principle plane changes. Therefore, the external load will not only 
be reported on the horizontal principle bending plane but also on the vertical principle bending plane due to the asymmetry created by the damage. In this case, the Smith method needs to be updated to include the progressively changing of the neutral axis rotations.

Fujikubo et al. (2012b) studied the influence of the neutral axis rotations on the damaged hull girders using the Smith's method, where they showed that the neutral axis rotations have a significant impact on the residual strength of asymmetrically damaged hulls which may reach as far as $8 \%$. Joonmo et al. (2012) adopted a different approach to deal with the translation and rotation of the neutral axis.

Makouei et al. (2015) have implemented the method of rotation of the neutral axis proposed by Fujikubo et al. (2012a) and validated it with the experiments of Lee et al. (2008) before studying the damaged hull of an Aframax. As the method is computationally inexpensive, it was used to perform calculations for a large set of damages building a response surface of the results. Li et al. (2018) also addressed the changes in the neutral axis during the progressive damage process in a Smith type of approach.

Tekgoz et al. (2018a) investigated the residual strength capacity of a grounded container ship under asymmetrical bending load using the Smith's method and accounting for the progressive neutral axis translations and rotations. They emphasized the fact that in the case of the residual strength capacity assessment of the hull girder, not only the size of the damage but also the location of the damage matters as well. It was demonstrated that as the damage centre moves away from the ship centre towards to the side shell of the ship, it gives more rise to the ultimate collapse capacity reductions due to the created asymmetry by the damage presence under the pure vertical bending moment (see Figure 11).

Numerous studies have also been presented performing finite element analyses to estimate the residual structural capacity of the ship hull girders by Ehlers et al. (2013); Kim et al. (2013); Yamada (2014); Tekgoz et al. (2015c, 2015a, 2015b); Parunov et al. (2018); Tekgoz et al. (2018b), and Corak and Parunov (2019).

\section{Ultimate Strength of Structures Subjected to Time-Varying Load}

\subsection{Plates and Stiffened Panels}

Ship's plating and its associated stiffener as a unit of the stiffened panel are exposed to a variety of external loads throughout the ship service life at sea. Hence, their structural behaviour and capacity resisting to different loads are to be well understood in the first place to enhance ship safety and protect the marine environment. Ships are predominantly subjected to

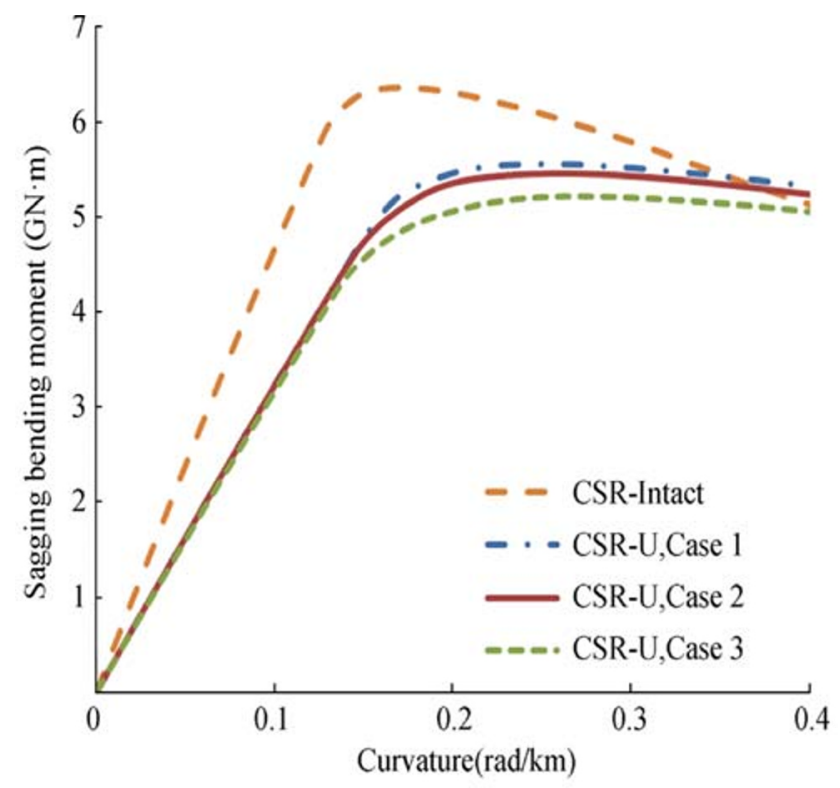

(a)

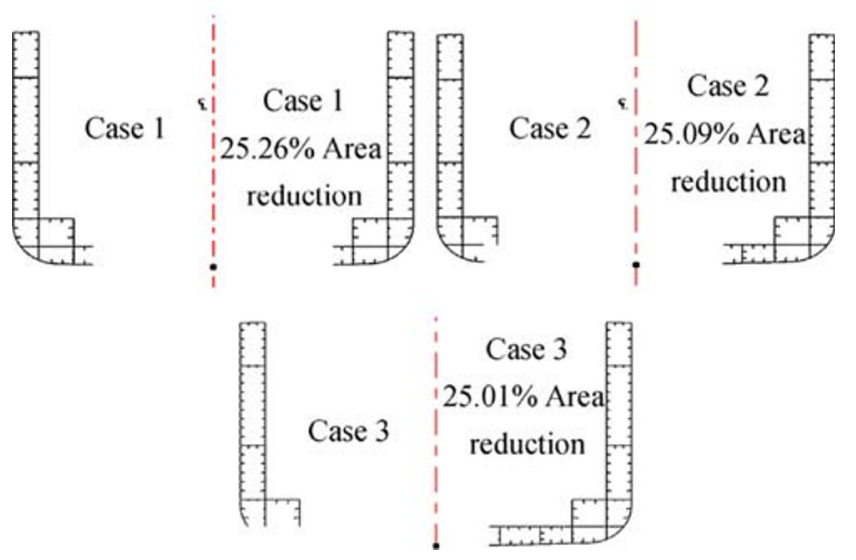

(b)

Figure 11 Residual sagging bending moment-curvature relationship, 0 degrees of heeling (a) and damage case studied (b) (Tekgoz et al. 2018a)

dynamic loads, which add to the complexity of the evaluation of the load capacity of the hull girder.

For example, Yao and Nikolov (1990) performed a series of elastic-plastic significant deflection analysis of plates subjected to cyclic loading, accounting for the impact of the cyclic load on the plate rigidity, re-yielding, and ultimate load capacity reduction in the case a wide plate. Goto et al. (1995) studied the influence of the localization of the plastic buckling, concluding that a significant reduction of the loading capacity of the steel structure under the cyclic load may be seen.

Paik and Thayamballi (2003) carried out an experimental investigation on a square plate subjected to various uniaxial loads with varying speed. They found that the ultimate strength capacity of the plate is correlated with the speed of the loading. As the speed of the loading increases, the ultimate 
strength and in-plane stiffness increase. In addition to that, they found that as the speed of the loading increases, the post-collapse regime of the plate structure gets steeper.

Komoriyama et al. (2018) studied the influence of the cumulative buckling under the cyclic load on the load capacity of the stiffened panels. They showed that when the cyclic compressive load is around the ultimate capacity of the structure, the cumulative buckling deformation is high. However, its impact on the ultimate load carrying capacity is small.

Yang et al. (2018a) analysed the ultimate dynamic strength of the ship plate structures under uniaxial compressive load. An empirical formula for predicting the ultimate dynamic compressive strength of ship plates, expressed in terms of the geometric dimensions of plates and impact speeds, was developed. Yang et al. (2018b) studied the influence of the uniaxial dynamic load combined with a lateral sea pressure on the ultimate strength of the outer double bottom stiffened plates. They analysed the influence of the mode shapes, initial imperfections, boundary conditions, and strain rates on the ultimate strength of the stiffened plates. They concluded that as the strain rate increases, which is correlated with the speed of the loading, the ultimate strength capacity of the stiffened plates increases. The dynamic ultimate load capacity of the rectangular plates has also been presented in Yang et al. (2019).

Tekgoz et al. (2019) and Tekgoz and Garbatov (2020b) studied the influence of the dynamic uniaxial compressive load on the ultimate load carrying capacity of a square plate where they presented that as the speed of the load increases, it gives rise to the load carrying capacity of the plate which might be more pronounced in the case of the aged steel plate. The cyclic behaviour of the rectangular plates has also been reported in Tekgoz and Garbatov (2020a), where they demonstrated the importance of the local plasticity effect on the cyclic strength of the rectangular plates (see Figure 12).

\subsection{Ship Structures}

In practice, the load carrying capacity of the hull girder is estimated based on the assumption that the structure is allowed to follow a path under a pure-bending load with an incrementally increasing curvature with a quasi-static structural response. The failure is considered to occur between two transverse frames enabling the problem to be treated in the 2D domain. However, these assumptions may not precisely represent the real collapse of the ship hull girder given the facts that the possibility of the exceedance of the structural capacity at any section, cumulative weakening effect of the ship hull girder with cyclic motions, the influence of the transverse load on the collapse behaviour of the stiffened panel components and the extent of the failure in combination with the sudden external loading such as whipping. Therefore, several studies have been reported on these issues.

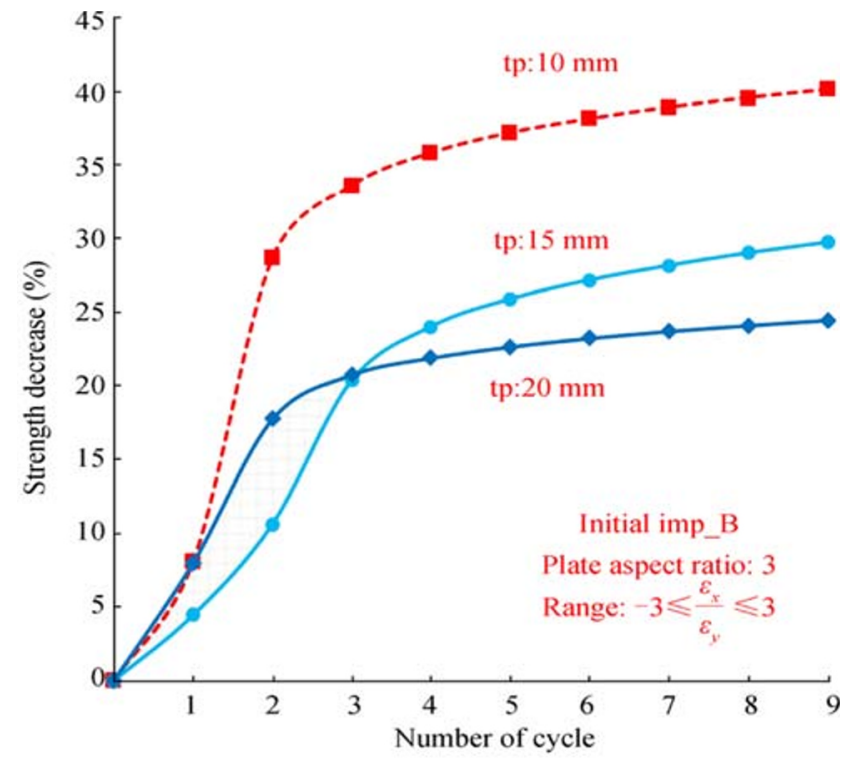

(a)

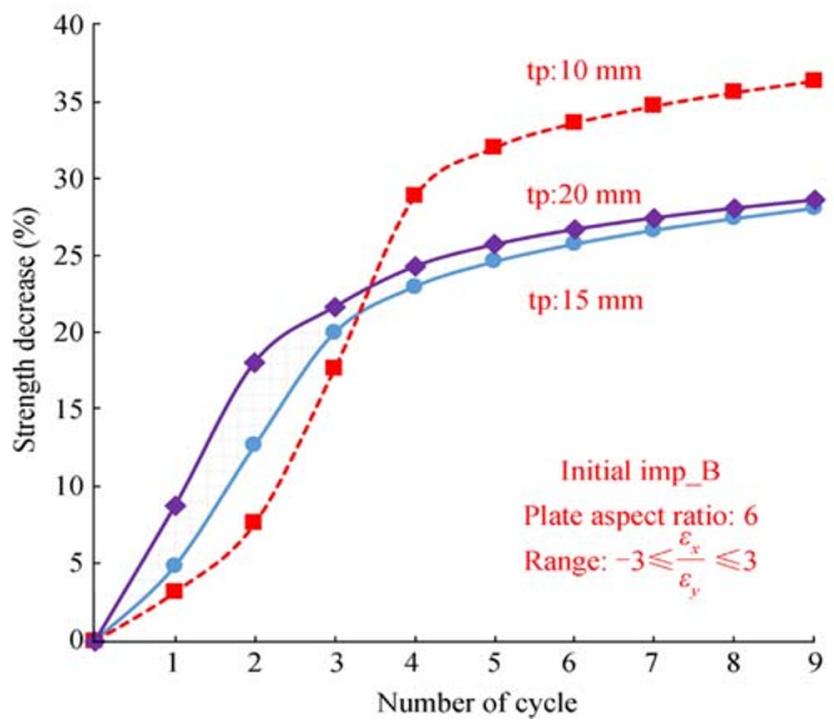

(b)

Figure 12 Ultimate capacity decrease as a function of cyclic load, plate aspect ratio 3 (a) and plate aspect ratio 6 (b) (Tekgoz and Garbatov, 2020a)

The dynamic collapse behaviour of a ship's hull girder in waves has been addressed by Iijima et al. (2011). They assumed that a plastic hinge would be formed during the collapse of the hull girder, induced by a dynamic wave load. This hinge was modelled as a non-linear rotational, and model tests have been made. Extensions of the study have been made by Iijima et al. (2015).

Pei et al. (2015) used a total simulation system as reported in Yao et al. (2009), which involves time-dependent pressure distribution and inertial forces that were applied to the bulk 
carrier to estimate the structural capacity in severe sea state using static and dynamic finite element formulations. They showed that the structural response predictions of the static and dynamic formulations are similar up to the ultimate strength.

Iijima et al. (2015) presented a scaled model test to predict the post-ultimate collapse behaviour of a ship's hull under whipping loads. They concluded that for the same amplitude of the load, the regular waves cause more considerable collapse extent compared to the one of the impact load. For the test model, the collapse behaviour under whipping load did not go into the unstable stage, yet the load exceeded the ultimate load capacity.

Derbanne et al. (2016) studied the ultimate dynamic strength of a ship's hull subjected to the whipping loads. They used a simple one degree of freedom model to analyse the non-linear dynamic response of the ship. They demonstrated that during the linear whipping response higher than the structural capacity, it does not necessarily lead to the hull girder collapse when a nonlinear structural model is used.

Yamada and Kameya (2018) investigated the ultimate dynamic strength of a container ship under the hogging bending moment accounting for the extent of the finite element model, namely, three full models, a half hold model, and one transverse model, and time duration. The external load has been applied in the form of a sinusoidal impulse load. Interesting findings have been presented that when the load duration is close to the natural period of the ship, and dynamic effects are active, the failure occurs in two frame spacing. If the duration is relatively longer, the failure took place in one frame space. They demonstrated that the ultimate dynamic strength of the ship is maximum when the load duration is around the natural period of the ship. They recommended that when the ultimate dynamic capacity of the ship is investigated using the finite element solution, a $1 / 2$ hold model or full ship model is recommended.

\section{Conclusions}

A review of advances in the ultimate strength assessment of corroded and damaged ship hull structures has been provided. The literature review showed that the structural behaviour of steel plates, stiffened panels, ship-shaped box girders, and ship hulls had been, to some extent, studied under different loading conditions. However, there should be more studies that may follow additional investigation on the impact of corrosion degradation on the structural behaviour of the stiffened panels and the overall hull girders to better understand the structural behaviour response accounting for potential external loadings. Studies related to understanding the dynamic collapse behaviour of corroded and damaged ship structures under time-variant load need more attention. Therefore, more related studies are required to increase the confidence level of the conventional methods in terms of their load capacity prediction accuracy, which are currently being used.

Open Access This article is licensed under a Creative Commons Attribution 4.0 International License, which permits use, sharing, adaptation, distribution and reproduction in any medium or format, as long as you give appropriate credit to the original author(s) and the source, provide a link to the Creative Commons licence, and indicate if changes were made. The images or other third party material in this article are included in the article's Creative Commons licence, unless indicated otherwise in a credit line to the material. If material is not included in the article's Creative Commons licence and your intended use is not permitted by statutory regulation or exceeds the permitted use, you will need to obtain permission directly from the copyright holder. To view a copy of this licence, visit http://creativecommons.org/licenses/by/4.0/.

\section{References}

Abdussamie N, Ojeda R, Dabaos M (2018) ANFIS method for ultimate strength prediction of unstiffened plates with pitting corrosion. Ships Offshore Struct 13:540-550

ABS (2002) ABS database of corrosion wastage for oil tankers, American Bureau of Shipping

Ahmmad MM, Sumi Y (2009) Strength and deformability of corroded steel plates under quasi-static tensile load. J Mar Sci Technol 15(1): $1-15$

Akpan UO, Koko TS, Ayyub B, Dunbar TE (2002) Risk assessment of aging ship hull structures in the presence of corrosion and fatigue. Mar Struct 15(3):211-231

Alinia MM, Hoseinzadeh SAA, Habashi HR (2007a) Influence of central cracks on buckling and post-buckling behaviour of shear panels. Thin-Walled Struct 45:422-431

Alinia MM, Hosseinzadeh SAA, Habashi HR (2007b) Numerical modelling for buckling analysis of cracked shear panels. Thin-Walled Struct 45(12):1058-1067

Amante DO, Chujutali JA, Estefen SF (2015) Experimental and numerical analyses of dented stiffened panels. J Offshore Mech Arct Eng 137(3):031601

Amlashi HKK, Moan T (2005) On the strength assessment of pitted stiffened plates under biaxial compression loading. In: Proceedings of the 24th International Conference on Offshore Mechanics and Arctic Engineering, 3, 83-92

Bayatfar A, Khedmati MR, Rigo P (2014) Residual ultimate strength of cracked steel unstiffened and stiffened plates under longitudinal compression. Thin-Walled Struct 84:378-392

Bayatfar A, Matagne J and Rigo P (2011) Influence of transverse cracks on ultimate strength of a steel plate under compression, In: Proceedings of the 30th International Conference on Ocean, Offshore and Arctic Engineering, 2, 643-650

Benson S, Abubakar A, Dow RS (2013) A comparison of computational methods to predict the progressive collapse behaviour of a damaged box girder. Eng Struct 48:266-280

Brighenti R (2005) Numerical buckling analysis of compressed or tensioned cracked thin plates. Eng Struct 27:265-276 
Campanile A, Piscopo V, Scamardella A (2016) Incidence of residual stresses and steel properties variability on corroded bulk carrier reliability. Ocean Eng 1281:58-80

Chujutalli JH, Estefen SF, Guedes Soares C (2020) Indentation parameters influence on the ultimate strength of panels for different stiffeners. J Constr Steel Res 170:106097

Corak M, Parunov J (2019) Structural reliability of oil tanker in the Adriatic Sea damaged in collision and exposed to combined bending. J Offshore Mech Arct Eng 142(3):1-32

Cui C, Yang P, Xia T, Du J (2016) Assessment of residual ultimate strength of cracked steel plates under longitudinal compression. Ocean Eng 121:174-183

Cui J, Wang DY (2020) An experimental and numerical investigation on ultimate strength of stiffened plates with opening and perforation corrosion. Ocean Eng 205:107282

Czujko J, Bayatfar A, Smith M, Xu MC, Wang D, Lützen M, SaadEldeen S, Yanagihara D, Notaro G, Qian X, Park JS, Broekhuijsen J, Benson S, Pahos S, Boulares J (2018) Committee III.1 Ultimate Strength. In: Proceedings of the 20th International Ship and Offshore Structures Congress (ISSC 2018), M. Kaminski and P. Rigo, IOS Press Ebooks, 1, 335-441

Czujko J, Brubak L, Czaban J, Johnson M, Kim GS, Pahos SJ, Tabri K, Tang WY, Waegter J, Yamada Y (2015) Committee V.1 on accidental limit states. In: Proceedings of the 19th international ship and offshore structures congress (ISSC 2015), C. Guedes Soares and Y. Garbatov, London, Taylor \& Francis, 519-590

Czujko J, Buannic N, Ehlers S, Hung C-F, Klaebo F, Pahos SJ, Riley M, Tang W, Vredeveldt A, Waegter J (2012) Committee V.1 on damage assessment following accidents. In: Proceedings of the 18th international ship and offshore structures congress (ISSC 2012), W. Fricke and R. Bronsart, Hamburg, Germany, Schiffbautechnische Gesellschaft e V, 1-65

Daidola J, Parente J, Orisamolu I (1997) Residual strength assessment of pitted plate panels. Ship Structural Committee, Report SSC-394

Derbanne Q, Lauzon JD, Bigot F, Malenica S (2016) Investigations of the dynamic ultimate strength of a ship's hull girder during whipping. In: Proceedings of PRADS2016, Denmark

Domzalicki P, Skalski I, Guedes Soares C, Garbatov Y (2009) Large scale corrosion tests, analysis and design of marine structures. In: Guedes Soares C, Das PK (eds) Analysis and design of marine structures. Taylor \& Francis Group, London, UK, pp 193-198

Dong Y, Frangopol DM (2015) Risk-informed life-cycle optimum inspection and maintenance of ship structures considering corrosion and fatigue. Ocean Eng 101:161-171

Dunbar TE, Pegg N, Taheri F, Jiang L (2004) A computational investigation of the effects of localized corrosion on plates and stiffened panels. Mar Struct 17(5):385-402

Ehlers S, Benson S, Misirlis K (2013) Ultimate strength of intact and damaged LNG vessel subjected to sub-zero temperature, collision and grounding of ships and offshore structures, I, pp 289-296

Feng L, He J, Hu L, Shi H, Yang S (2020) A parametric study on effects of pitting corrosion on steel plate's ultimate strength. Appl Ocean Res 95:102026

Fujikubo M, Takemura K, Oka S, Alie AZM, Ijima K (2012a) Residual Hull girder strength of asymmetrically damaged ships -influence of rotation of neutral axis due to damages. J Soc Naval Archit Ocean Eng 16:131-140

Fujikubo M, Takemura K, Oka S, Alie MZM, Iijima K (2012b) Residual hull girder strength of asymmetrically damaged ships. J Japan Soc Naval Archit Ocean Eng 16:131-140

Garbatov Y (2016) Fatigue strength assessment of ship structures accounting for a coating life and corrosion degradation. Int J Struc Integ 7(2):305-322

Garbatov Y, Guedes Soares C (2008) Corrosion wastage modelling of deteriorated bulk carrier decks. Int Shipbuild Prog 55(1-2):109-125
Garbatov Y, Guedes Soares C (2009a) Corrosion wastage statistics and maintenance planning of corroded hull structures of bulk carriers, analysis and design of marine structures. In: Guedes Soares C, Das PK (eds) Analysis and design of marine structures. Taylor \& Francis Group, London, UK, pp 215-222

Garbatov Y, Guedes Soares C (2009b) Structural maintenance planning based on historical data of corroded deck plates of tankers. Reliab Eng Syst Saf 94(11):1806-1817

Garbatov Y, Guedes Soares C (2010) Maintenance Planning for the Decks of Bulk Carriers and Tankers, in: Furuta, H. Frangopol D. M. Shinozuka M. (eds) Reliability and Risk of Structures, Infrastructures and Engineering Systems. Taylor \& Francis Group, London, pp 3517-3524

Garbatov Y, Guedes Soares C (2011) Reliability based maintenance of marine Structures. In: Guedes Soares C, Garbatov Y, Fonseca N, Teixeira AP (eds) Marine technology and Engineering, vol 2. Taylor \& Francis Group, London, 1101-1120

Garbatov Y, Guedes Soares C (2016) Reliability of deteriorated marine structures based on measured data. Int Jf Maritime Eng 158(A4): A281-A288

Garbatov Y, Guedes Soares C (2017) Fatigue reliability of dented pipeline based on limited experimental data. Int J Press Vessel Pip 155: $15-26$

Garbatov Y, Guedes Soares C (2019) Spatial corrosion wastage modelling of steel plates exposed to marine environments. J Offshore Mech Arct Eng 141(3):031602

Garbatov Y, Guedes Soares C, Parunov J (2014a) Fatigue strength experiments of corroded small scale steel specimens. Int J Fatigue 59: $137-144$

Garbatov Y, Guedes Soares C, Parunov J, Kodvanj J (2014b) Tensile strength assessment of corroded small scale specimens. Corros Sci 85:296-303

Garbatov Y, Guedes Soares C, Wang G (2007) Nonlinear time-dependent corrosion wastage of deck plates of ballast and cargo tanks of tankers. J Offshore Mech Arct Eng 129(1):48-55

Garbatov Y, Parunov J, Kodvanj J, Saad-Eldeen S, Guedes Soares C (2016a) Experimental assessment of tensile strength of corroded steel specimens subjected to sandblast and sandpaper cleaning. Mar Struct 49:18-30

Garbatov Y, Saad-Eldeen S, Guedes Soares C, Parunov J, Kodvanj J (2019) Tensile test analysis of corroded cleaned aged steel specimens, corrosion engineering. Sci Technol 54(2):154-162

Garbatov Y, Tekgoz M, Guedes Soares C (2016b) Experimental and numerical strength assessment of stiffened plates subjected to severe non-uniform corrosion degradation and compressive load. Ships Offshore Struct 12(4):461-473

Gardiner C, Melchers R (2002) Corrosion of mild steel by coal and iron ore. Corros Sci 44:2665-2673

Gordo JM, Guedes Soares C (2000) Residual strength of damaged ship hulls. In: Proceedings of the IX International Maritime Association of Mediterranean Congress (IMAM2000) Ischia, Italy, 79-86

Goto Y, Toba Y, Matsuoka H (1995) Localization of plastic buckling patterns under cyclic loading. J Eng Mech 121(4):493-501

Guedes Soares C (1988) Uncertainty modelling in plate buckling. Struct Saf 5:17-34

Guedes Soares C, Garbatov Y (1996a) Fatigue reliability of the ship hull girder accounting for inspection and repair. Reliab Eng Syst Saf 51(3):341-351

Guedes Soares C, Garbatov Y (1996b) Reliability of maintained ship hulls subjected to corrosion. J Ship Res 40(3):235-243

Guedes Soares C, Garbatov Y (1997) Reliability assessment of maintained ship hulls with correlated corroded elements. Mar Struct 10(8-10):629-653

Guedes Soares C, Garbatov Y (1998a) Nonlinear time-dependent model of corrosion for the reliability assessment of maintained structural 
components. In: Lydersen S, Hansen GK, Sandtov HA (eds) Safety and reliability, vol 2. A. A. Balkema, Rotterdam, the Netherlands, 928-936

Guedes Soares C, Garbatov Y (1998b) Reliability of maintained ship hull girders subjected to corrosion and fatigue. Struct Saf 20(3):201-219

Guedes Soares C, Garbatov Y (1999a) Reliability of maintained ship hull girders of two bulk carriers designs subjected to fatigue and corrosion. J Ship Ocean Technol 3:27-41

Guedes Soares C, Garbatov Y (1999b) Reliability of maintained, corrosion protected plates subjected to non-linear corrosion and compressive loads. Mar Struct 12(6):425-445

Guedes Soares C, Garbatov Y, Zayed A (2013) Effect of environmental factors on steel plate corrosion under marine immersion conditions, corrosion engineering. Sci Technol 46(4):524-541

Guedes Soares C, Garbatov Y, Zayed A, Wang G (2005) Non-linear corrosion model for immersed steel plates accounting for environmental factors. Transac Soc Naval Archit Marine Eng 113:306-322

Guedes Soares C, Basu R, Simonsen BC, Egorov GV, Hung CF, Lindstrom P (2009a) Committee V.1: Damage Assessment After Accidental Events, In: Proceedings of 17th International Ship and Offshore Structures Congress (ISSC2009), C. Jang and S. Hong, Seoul, South Korea, University of Seoul, 2:1-73

Guedes Soares C, Garbatov Y, Zayed A, Wang G (2009b) Influence of environmental factors on corrosion of ship structures in marine atmosphere. Corros Sci 51(9):2014-2026

Guedes Soares C, Garbatov Y, Zayed A, Wang G (2008a) Corrosion wastage model for ship crude oil tanks. Corros Sci 50(11):30953106

Guedes Soares C, Luís RM, Teixeira AP, Quesnel T, Nikolov PI, Steen E, Khan IA, Toderan C, Olaru VD, Bollero A, Taczala M (2008b) Parametric study on the collapse strength of rectangular plates with localized imperfections under in-plane compression. Int Shipbuild Prog 55:63-5585

Guo J, Wang G, Ivanov L, Perakis AN (2008) Time-varying ultimate strength of aging tanker deck plate considering corrosion effect. Mar Struct 21(4):402-419

Guo J, Wang G, Perakis AN, Ivanov LD (2012) A study on reliabilitybased inspection planning - application to deck plate thickness measurement of aging tankers. Mar Struct 25:85-106

Hart D, Rutherford S, Wichham A (1986) Structural reliability analysis of stiffened panels. Transac Royal Institut Naval Archit 128:293-310

Heyer A, D'Souza F, Leon Morales CF, Ferrari G, de Wit JHW (2013) Ship ballast tanks a review from microbial corrosion and electrochemical point of view. Ocean Eng 70:188-200

Höfer T (2003) Tanker safety and coastal environment: Prestige, Erika, and what else? Environ Sci Pollut Res Int 10:1-5

Hu W, Lin Y, Yuan S, Z. H (2015) Constitutive models for regression of various experimental stress-strain relations. Int J Mech Sci 1-9:101102

Hu Y, Cui WC, Pedersen PT (2004) Maintained ship hull girder ultimate strength reliability considering corrosion and fatigue. Mar Struct 17(2):91-123

Hua J, Cheng C (2013) Corrosion of high tensile steel on board bulk carrier loaded with coal of different origins. Ocean Eng 69:24-33

Huang W, Garbatov Y, Guedes Soares C (2014) Fatigue reliability of a web frame subjected to random non-uniform corrosion wastage. Struct Saf 48:51-62

Huang Y, Zhang G, Liu G, Zhang Q (2010) Ultimate strength assessment of hull structural plate with pitting corrosion danification under biaxial compression. Ocean Eng 37(17-18):1503-1512

Hussein AW, Guedes Soares C (2009) Reliability and residual strength of double hull tankers designed according to the new IACS common structural rules. Ocean Eng 36:1446-1459

Iijima K, Kimura K, Xu W, Fujikubo M (2011) Hydroelastoplasticity approach to predicting the post-ultimate strength behaviour of a Ship's Hull girder in waves. J Mar Sci Technol 16(4):379-389
Iijima K, Suzaki Y, Fujikubo M (2015) Scaled tests for the post-ultimate strength collapse behaviour of a ship's hull girder under whipping loads. Ships Offshore Struct 10:31-38

IMO (2010) Adoption of the international goal-based ship construction standards for bulk carriers and oil tankers. Maritime Safety Commit 287(87)

Islam MR, Sumi Y (2011) Geometrical effects of pitting corrosion on strength and deformability of steel rectangular plates subjected to uniaxial tension and pure bending, Journal of the Society of Naval Architects of Japan, 9-17

Ivanov L, Spencer J, Wang G (2003) Probabilistic evaluation of hull structure renewals for aging ships. ABS Technical Papers 2003: 329-342

Jelovica J, Romanoff J, Ehlers S, Aromaa J (2013) Ultimate strength of corroded web-core sandwich beams. Mar Struct 31:1-14

Jelovica J, Romanoff J, Remes H (2014) Influence of general corrosion on buckling strength of laser-welded web-core sandwich plates. J Constr Steel Res 101:342-350

Jia H, Moan T (2008) Reliability analysis of oil tankers with collision damage. In: Proceedings of the 27th International Conference on Offshore Mechanics and Arctic Engineering paper OMAE200857102, 55-63

Jia Z, Yang Y, He Z, Ma H, Ji F (2019) Mechanical test study on corroded marine high-performance steel under cyclic loading. Appl Ocean Res 93(101942): 101942

Jiang X, Guedes Soares C (2008) Assessment of the uncertainty in corrosion models for ship steels, In: Proceedings of 27th international conference on offshore mechanics and Arctic engineering (OMAE 2008), Estoril, Portugal, ASME, paper OMAE2008-58052

Jiang X, Guedes Soares C (2011) Ultimate capacity behaviour of pitted mild steel plates under biaxial compression. In: Proceedings of the 30th International Conference on Ocean, Offshore and Arctic Engineering (OMAE 2011), Rotterdam, the Netherlands, ASME, paper OMAE2011-49980

Jiang X, Guedes Soares C (2012) Ultimate capacity of rectangular plates with partial depth pits under uniaxial loads. Mar Struct 26(1):27-41

Joonmo C, Nam JM, Ha TB (2012) Assessment of residual ultimate strength of an asymmetrically damaged tanker considering rotational and translational shifts of neutral axis plane. Mar Struct 25:71-84

Khedmati MR, Edalat P, Javidruzi M (2009) Sensitivity analysis of the elastic buckling of cracked plate elements under axial compression. Thin-Walled Struct 47:522-536

Khedmati MR, Hadj Z, Nouri ME (2015) Analytical simulation of nonlinear elastic-plastic average stress-average strain relationships for un-corroded/both-sides randomly corroded steel plates under uniaxial compression. Thin-Walled Struct 86:132-141

Khedmati MR, Roshanali MM, Nouri ZHME (2011) Strength of steel plates with both-sides randomly distributed with corrosion wastage under uniaxial compression. Thin-Walled Structure 49:325-342

Kim DK, Kim HB, Mohd MH, Paik JK (2013) Comparison of residual strength - grounding damage index diagrams for tankers produced by the ALPS/HULL ISFEM and design formula method. Int J Naval Archit Ocean Eng 5:47-61

Kim DK, Liew MS, Youssef SAM, Mohd MH, Kim HB, Paik JK (2014) Time-dependent ultimate strength performance of corroded FPSOs. Arab J Sci Eng 39(11):7673-7690

Kim U-N, Choe I-H, Paik JK (2009) Buckling and ultimate strength of perforated plate panels subject to axial compression: experimental and numerical investigations with design formulations. Ships Offshore Struct 4:337-361

Komoriyama Y, Tanaka Y, Ando T, Hashizume Y, Tatsumi A, Fujikubo M (2018) Effects of cumulative buckling deformation formed by cyclic loading on ultimate strength of stiffened panel. In: Proceedings of the 37th International Conference on Ocean, Offshore and Arctic Engineering, paper OMAE2018-77855 
Lampe J, Hamann R (2018) Probabilistic model for corrosion degradation of tanker and bulk carrier. Mar Struct 61:309-325

Lee T-K, Rim CW, Han D-S, Kim BH, Lee J-M, Kim KS (2008) A study of ultimate collapse strength in sagging of ship structures with side collision damage, International Offshore and Polar Engineering Conference, Vancouver, BC, Canada, 503-508

Li CF, Fu P, Ren HL, Xu WJ, Guedes Soares C (2018) Ultimate bearing capacity assessment of hull girder with asymmetric cross-section. J Offshore Mech Arct Eng 140

Liu B, Garbatov Y, Zhu L, Guedes Soares C (2018a) Numerical assessment of the structural crashworthiness of corroded ship hulls in stranding. Ocean Eng 170:276-285

Liu B, Pedersen P, Zhu L, Zhang S (2018b) Review of experiments and calculation procedures for ship collision and grounding damage. Mar Struct 59:105-121

Luis RM, Guedes Soares C, Nikolov PI (2008) Collapse strength of longitudinal plate assemblies with dimple imperfections. Ships Offshore Struct 3:359-370

Luis RM, Teixeira AP, Guedes Soares C (2009) Longitudinal strength reliability of a tanker hull accidentally grounded. Struct Saf 31:224 233

Ma H, Yang Y, He Z, Zhang Y, Ji F (2019) Experimental study on mechanical properties of steel under extreme cyclic loading considering pitting damage. Ocean Eng 186(106091):106091

Makouei SH, Teixeira AP, Guedes Soares C (2015) A study on the progressive collapse behaviour of a damaged hull girder. In: Guedes Soares, C, Santos T.A. (Eds.). Maritime Technology and Engineering London, Taylor \& Francis Group, 405-416

Mansour AE, El-Kilani HS, Abdel-Malek IS (2003) Residual strength of ships after grounding. Alexandria Eng J 42(5):517-525

Margaritis Y, Toulios M (2012) The ultimate and collapse response of cracked stiffened plates subjected to uniaxial compression. ThinWalled Struct 50:157-173

Mateus AF, Witz JA (1998) On the post-buckling of corroded steel plates used in marine structures. Transac Royal Institut Naval Archit 140: $165-183$

Melchers RE (2003a) Probabilistic models for corrosion in structural reliability assessment — part 1: empirical models. J Offshore Mech Arct Eng 125(4):264-271

Melchers RE (2003b) Probabilistic models for corrosion in structural reliability assessment-part 2: models based on mechanics. J Offshore Mech Arct Eng 125(4):272-280

Mohammadrahimi A, Sayebani M (2019) Using the Bayesian updating approach to develop time-dependent corrosion wastage model for deck panel of bulk carriers. Mar Struct 64:92-109

Nakai T, Matsushita H, Yamamoto N (2006) Effect of pitting corrosion on the ultimate strength of steel plates subjected to in-plane compression and bending. J Mar Sci Technol 11(1):52-64

Nakai T, Matsushita H, Yamamoto N (2007) Visual assessment of corroded condition of plates with pitting corrosion takin into account residual strength-in the case of webs of hold frames of bulk carriers. In: Proceedings of the 26th International Conference on Offshore Mechanics and Arctic Engineering, OMAE2007-29159, 1-11

Nikolov PI (2007) Collapse strength of damaged plating between stiffeners, in: Guedes Soares, C. Kolev, P (Eds) Maritime Industry, Ocean Engineering and Coastal Resources. Taylor \& Francis Group, London, pp 237-244

Nikolov PI (2008) Collapse strength of damaged plating. In: Proceedings of the 27th International Conference on Offshore Mechanics and Arctic Engineering, Estoril, Portugal, ASME, OMAE2008-57119, $79-88$

Ok D, Pu Y, Incecik A (2007) Artificial neural networks and their application to assessment of ultimate strength of plates with pitting corrosion. Ocean Eng 34:2222-2230
Paik JK (2008) Residual ultimate strength of steel plates with longitudinal cracks under axial compression-experiments. Ocean Eng 35(1718): $1775-1783$

Paik J, Brennan F, Carlsen C, Daley C, Garbatov Y, Ivanov L, Rizzo C, Simonsen B, Yamamoto N. Zhuang H (2006a) Committee V.6 Condition assessment of aged ships, in: Proceedings of the 16th International Ship and Offshore Structures Congress (ISSC2006), P. Frieze and R. Shenoi, Southampton, U.K., University of Southampton 2:255-306

Paik JK, Kumar YV (2006b) Ultimate strength of stiffened panels with cracking damage under axial compression or tension. J Ship Res 50(3):231-238

Paik JK, Kim S, Lee S, Park Y (1998) A probabilistic corrosion rate estimation model for longitudinal strength members of bulk carriers. J Ship Ocean Technol 2:58-70

Paik JK, Kumar YV, Lee JM (2005) Ultimate strength of cracked elements under axial compression or tension. Thin-Walled Struct 43: 237-272

Paik JK, Lee JM, Hwang JS, Park Y 1 (2003a) A time-dependent corrosion wastage model for the structures of single and double hull tankers and FSOs and FPSOs. Mar Technol 40(3):201-217

Paik JK, Lee JM, Ko MJ (2003b) Ultimate compressive strength of plate element with pit corrosion wastage. Jf Eng Maritime Environ 217: 185-200

Paik JK, Lee JM, Ko MJ (2004) Ultimate shear strength of plate element with pit corrosion wastage. Thin-Walled Struct 42:1161-1176

Paik JK, Lee JM, Lee DH (2003c) Ultimate strength of dented steel plates under axial compressive loads. Int J Mech Sci 45:433-448

Paik JK, Lee JM, Park Y II, Hwang JS, Kim CW (2003d) Time-variant ultimate longitudinal strength of corroded bulk carriers. Mar Struct 16(8):567-600

Paik JK, Mansour AE (1995) A simple formulation for predicting the ultimate strength of ships. J Mar Sci Technol 1:52-62

Paik JK, Thayamballi AK (2003) An experimental investigation on the dynamic ultimate compressive strength of ship plating. International Journal of Impact Engineering 28(7):803-811

Panayotova M, Garbatov Y, Guedes Soares C (2004a) Factors influencing atmospheric corrosion and corrosion in closed spaces of marine steel structures. In: Proceedings of the International Conference on Marine Science and Technology (Black Sea'04), Varna, Bulgaria, Union of Scientists of Varna, 286-292

Panayotova M, Garbatov Y, Guedes Soares C (2004b) Factors influencing corrosion of steel structural elements immersed in seawater. In: Proceedings of the International Conference on Marine Science and Technology (Black Sea' 04), Varna, Bulgaria, Union of Scientists of Varna, 280-286

Panayotova M, Garbatov Y, Guedes Soares C (2008a) Corrosion monitoring of ship hulls, in: Guedes Soares, C. Kolev, P (Eds) Maritime Industry, Ocean Engineering and Coastal Resources. Taylor \& Francis Group, London, pp 263-269

Panayotova M, Garbatov Y, Guedes Soares C (2008b) Corrosion of steels in marine environment, monitoring and standards, in: Guedes Soares, C. Safety and Reliability of Industrial Products, Systems and Structures, Taylor \& Francis Group, London, pp 369-412

Parunov J, Gledic I, Garbatov Y, Guedes Soares C (2013) Fatigue assessment of corroded deck longitudinals of tankers. Int J Maritime Eng 155(A1):9-21

Parunov J, Rudan S, Gledic I, Primorac BB (2018) Finite element study of residual ultimate strength of a double hull oil tanker with simplified collision damage and subjected to biaxial bending. Ships Offshore Struct 13:525-536

Pei Z, Iijima K, Fujikubo M, Tanaka S, Okazawa S, Yao T (2015) Simulation on progressive collapse behaviour of whole ship model under extreme waves using idealized structural unit method. Mar Struct 40:104-133 
Piscopo V, Scamardella A (2018) Towards a unified formulation for the ultimate strength assessment of uncorroded and pitted platings under uniaxial compression. Ocean Eng 1691:70-86

Qin S, Cui W (2002) Effect of corrosion models on the time-dependent reliability of steel plated elements. Mar Struct 15-34

Qin G, Xu S, Yao D, Zhang Z (2016) Study on the degradation of mechanical properties of corroded steel plates based on surface topography. J Constr Steel Res 125:205-217

Rahbar-Ranji A (2012) Ultimate strength of corroded steel plates with irregular surfaces under in-plane compression. Ocean Eng 54:261269

Rahbar-Ranji A (2015) Elastic buckling analysis of corroded stiffened plates with irregular surfaces. Sadhana 40(1):199-213

Raviprakash AV, Prabu B, Alagumurthi N (2012) Residual ultimate compressive strength of dented square plates. Thin-Walled Struct 58:3239

Riks E, Rankin CC, Bargon FA (1992) Buckling behaviour of a central crack in a plate under tension. Eng Fract Mech 43:529-548

Rutherford SE, Caldwell JB (1990) Ultimate longitudinal strength of ships: a case study. Trans SNAME 89:441-471

Saad-Eldeen S, Garbatov Y, Guedes Soares C (2010) Experimental assessment of the ultimate strength of a box girder subjected to fourpoint bending moment. In: Proceedings of the 11th International Symposium on Practical Design of Ships and other Floating Structures (PRADS2010), Rio de Janeiro, Brazil, Aped, 1134-1143

Saad-Eldeen S, Garbatov Y, Guedes Soares C (2011a) Corrosiondependent ultimate strength assessment of aged box girders based on experimental results. J Ship Res 55(4):289-300

Saad-Eldeen S, Garbatov Y, Guedes Soares C (2011b) Experimental assessment of the ultimate strength of a box girder subjected to severe corrosion. Mar Struct 24(4):338-357

Saad-Eldeen S, Garbatov Y, Guedes Soares C (2012) Analysis of plate deflections during ultimate strength experiments of corroded box girders. Thin-Walled Struct 54:164-176

Saad-Eldeen S, Garbatov Y, Guedes Soares C (2013a) Effect of corrosion severity on the ultimate strength of a steel box girder. Eng Struct 49: $560-571$

Saad-Eldeen S, Garbatov Y, Guedes Soares C (2013b) Ultimate strength assessment of corroded box girders. Ocean Eng 58:35-47

Saad-Eldeen S, Garbatov Y, Guedes Soares C (2014) Strength assessment of a severely corroded box girder subjected to bending moment. J Constr Steel Res 92:90-102

Saad-Eldeen S, Garbatov Y, Guedes Soares C (2015a) Compressive strength assessment of rectangular steel plates accounting for the presence of a local dent or an opening, in: Guedes Soares C. and Santos, TA (eds) Maritime Technology and Engineering, London, UK, Taylor \& Francis Group, 543-551

Saad-Eldeen S, Garbatov Y, Guedes Soares C (2015b) Strength assessment of steel plates subjected to compressive load and dent deformation. Struct Infrastruct Eng 12(8):995-1011

Saad-Eldeen S, Garbatov Y, Guedes Soares C (2016) Experimental investigation on the residual strength of thin steel plates with a central elliptic opening and locked cracks. Ocean Eng 115:19-29

Saad-Eldeen S, Garbatov Y, Guedes Soares C (2019) Buckling collapse tests of deteriorated steel plates with multiple circular openings. Ocean Eng 172:523-530

Saad-Eldeen S, Garbatov Y, Guedes Soares C (2013c) Effect of corrosion degradation on ultimate strength of steel box girders, corrosion engineering. Sci Technol 47(4):272-283

Saad-Eldeen S, Guedes Soares C (2009) Effect of pitting corrosion on the collapse strength of rectangular plates under axial compression. in: Guedes Soares, C \& Das P. K., (Eds.). Analysis and Design of Marine Structures. London, U.K. Taylor \& Francis Group; 231-236

Sadovský Z, Drdácký M (2001) Buckling of plate strip subjected to localised corrosion - a stochastic model. Thin-Walled Struct 39(3): 247-259
Shaw D, Huang YH (1990) Buckling behaviour of a central cracked thin plate under tension. Eng Fract Mech 35(6):1019-1027

Sheng J, Xia J (2017) Effect of simulated pitting corrosion on the tensile properties of steel. Constr Build Mater 131:90-100

Shi G-J, Wang DY (2012) Residual ultimate strength of cracked box girders under torsional loading. Ocean Eng 43:102-112

Shi W (1993) In-service assessment of ship structures: effects of general corrosion on ultimate strength. Transac Royal Institut Naval Archit 135:77-91

Shi G, Wang DY (2012) Residual ultimate strength of open box girders with cracked damage. Ocean Eng 43:90-101

Shi XH, Zhang J, Guedes Soares C (2019) Numerical assessment of experiments on the residual ultimate strength of stiffened plates with a crack. Ocean Eng 171:443-457

Shi XH, Jiang X, Zhang J, Guedes Soares C (2016) Residual ultimate strength of stiffened panels with pitting corrosion under compression. In: Guedes Soares, C. \& Santos T. A., (Eds.). Maritime Technology and Engineering 3. London, UK: Taylor \& Francis Group; 547-556

Shi XH, Zhang J, Guedes Soares C (2017) Experimental study on collapse of cracked stiffened plate with initial imperfections under compression. Thin-Walled Struct 114:39-51

Shi XH, Zhang J, Guedes Soares C (2018) Numerical assessment of experiments on the ultimate strength of stiffened panels with pitting corrosion under compression. Thin-Walled Struct 133:52-70

Silva JE, Garbatov Y, Guedes Soares C (2013) Ultimate strength assessment of rectangular steel plates subjected to a random localised corrosion degradation. Eng Struct 52:295-305

Silva JE, Garbatov Y, Guedes Soares C (2014) Reliability assessment of a steel plate subjected to distributed and localized corrosion wastage. Eng Struct 59:13-20

Slater PA, Pandey MD, Sherbourne AN (1999) Finite element analysis of buckling of corroded ship plates. Can J Civ Eng 27:463-474

Smith CS, Dow RS (1981) Residual strength of damaged steel ships and offshore structure. J Constr Steel Res 1(4):2-15

Southwell C, Bultman J, Hummer JRC (1979) Estimating of service life of steel in seawater. In: Seawater Corrosion Handbook, 374-387

Sultana S, Wang Y, Sobey AJ, Wharton JA, Shenoi RA (2015) Influence of corrosion on the ultimate compressive strength of steel plates and stiffened panels. Thin-Walled Struct 96:95-104

Sumi Y (2008) Strength and deformability of corroded steel plates estimated by replicated specimens. J Ship Product Desig 24(3):161-167

Sumi Y, Yamamura N, Yamamuro Y (2006) On the strength and deformability of corroded steel. J Japan Soc Naval Archit Ocean Eng 4:239-245

Sun HH, Guedes Soares C (2006) Reliability-based inspection for corroded ship-type FPSO hulls. J Ship Res 50(2):171-180

Teixeira AP, Guedes Soares C (2008) Ultimate strength of plates with random fields of corrosion. Struct Infrastruct Eng 4(5):363-370

Tekgoz M, Garbatov Y (2020a) Strength assessment of rectangular plates subjected to extreme cyclic load reversals. J Marine Sci Eng 8(2):65, $1-65,21$

Tekgoz M, Garbatov Y (2020b) Strength assessment of rectangular plates subjected to extreme cyclic load reversals. J Marine Sci Eng 8(2):65

Tekgoz M, Garbatov Y, Guedes Soares C (2015a) Strength analysis of ship shaped structures subjected to asymmetrical bending moment, in: Guedes Soares C. and Shenoi A. (eds) Analysis and Design of Marine Structures, Taylor \& Francis Group, London, 415-423

Tekgoz M, Garbatov Y, Guedes Soares C (2015b) Strength assessment of a single hull damaged tanker ship subjected to asymmetrical bending loading, in: Guedes Soares, C.. Dejhalla R and Pavletic D. (eds) Towards Green Marine Technology and Transport, London, Taylor \& Francis Group, 327-334

Tekgoz M, Garbatov Y, Guedes Soares C (2015c) Ultimate strength assessment of a container ship accounting for the effect of neutral axis movement, in: Guedes Soares C, Santos TA. (eds) Marine 
Technology and Engineering, London, Taylor \& Francis Group, 417-425

Tekgoz M, Garbatov Y, Guedes Soares C (2018a) Residual strength assessment of a grounded container ship subjected to asymmetrical bending loads, in: Guedes Soares C, Santos TA (eds) Progress in Maritime Technology and Engineering, London, Taylor \& Francis Group, 337-344

Tekgoz M, Garbatov Y, Guedes Soares C (2018b) Strength assessment of an intact and damaged container ship subjected to asymmetrical bending loadings. Mar Struct 58:172-198

Tekgoz M, Garbatov Y, Guedes Soares C (2019) Ultimate strength assessment of a square plate subjected to uniaxial dynamic load, in: Guedes Soares, C. (ed) Developments in the Collision and Grounding of Ships and Offshore Structures. Taylor and Francis Group, London, 189-201

TSCF (1992) Condition evaluation and maintenance of tanker structures. Wetherby \& Co, London

Vafai A, Javidruzi M, Estekanchi HE (2002) Parametric instability of edge cracked plates. Thin-Walled Struct 40:29-44

Wang F, Cui WC, Paik JK (2009a) Residual ultimate strength of structural members with multiple crack damage. Thin-Walled Struct 47(12):1439-1446

Wang G, Boon B, Brennan F, Garbatov Y, Ji C, Parunov J, Rahman T, Rizzo C, Rouhan A, Shin C, Yamamoto N (2009) Committee V.6 Condition assessment of ageing ships and offshore structures, In: (eds) Proceedings of the 17th International Ship and Offshore Structures Congress (ISSC2009), C. Jang, J. Hong J, Seul, South Korea, University of Seoul, 3

Wang F, Paik JK, Kim BJ, Weicheng C, Tasawar H, Ahmad B (2015a) Ultimate shear strength of intact and cracked stiffened panels. ThinWalled Struct 88:48-57

Wang G, Lee A, Ivanov L, Lynch J, Serratella C, Basu R (2008) A statistical investigation of time-variant hull girder strength of aging ships and coating life. Mar Struct 21:240-256

Wang G, Spencer J, Elsayed T (2003) Estimation of corrosion rates of structural members in oil tankers. In: Proceeding of $22 \mathrm{nd}$ International Conference on Offshore Mechanics and Arctic Engineering, paper OMAE2003-37361, ASME

Wang R, Shenoi R, Sobey A (2018) Ultimate strength assessment of plated steel structures with random pitting corrosion damage. J Constr Steel Res 143:331-342

Wang Y, Wharton JA, Shenoi RA (2015b) Ultimate strength assessment of steel stiffened plate structures with grooving corrosion damage. Eng Struct 941:29-42

Wang Y, Wharton Y, Shenoi R (2014) Ultimate strength analysis of aged steel-plated structures exposed to marine corrosion damage: a review. Corros Sci 86:42-60

Wirsching PH, Ferensic J, Thayamballi A (1998) Reliability with respect to ultimate strength of a corroding ship Hull. Mar Struct 10(7):501518

Witkowska M, Guedes Soares C (2015) Ultimate strength of locally damaged panels. Thin Walled Structures 97:225-240

Woloszyk K, Garbatov Y (2019) Structural reliability assessment of corroded tanker ship based on experimentally estimated ultimate strength. Polish Maritime Res 26(2):47-54

Woloszyk K, Garbatov Y (2020) Random field modelling of mechanical behaviour of corroded thin steel plate specimens. Eng Struct 212: 110544

Woloszyk K, Kahsin M, Garbatov Y (2018) Numerical assessment of ultimate strength of severe corroded stiffened plates. Eng Struct 168:346-354

Xu MC, Garbatov Y, Guedes Soares C (2014) Residual ultimate strength assessment of stiffened panels with locked cracks. Thin-Walled Struct 85:398-410
Xu MC, Guedes Soares C (2013) Assessment of residual ultimate strength for wide dented stiffened panels subjected to compressive loads. Eng Struct 49:316-328

Xu MC, Guedes Soares C (2015) Effect of a central dent on the ultimate strength of narrow stiffened panels under axial compression. Int $\mathrm{J}$ Mech Sci 100:68-79

Xu S-H, Qiu B (2013) Experimental study on fatigue behaviour of corroded steel. Mater Sci Eng A584:163-169

Xu S, Wang H, Li A, Wang Y, Su L (2016) Effects of corrosion on surface characterisation and mechanical properties of butt-welded joints. J Constr Steel Res 126:50-62

Yamada Y (2014) Numerical study on the residual ultimate strength of hull girder of a bulk carrier after ship-ship collision. In: Proceedings of the 33rd International Conference on Offshore Mechanics and Arctic Engineering, paper OMAE2014-23811

Yamada Y, Kameya K (2018) A study on the dynamic ultimate strength of global hull girder of container ships subjected to hogging moment. In: Proceedings of the 37th International Conference on Ocean, Offshore and Arctic engineering, paper OMAE2018-77402

Yamada Y, Takami T (2015) Model test on the ultimate longitudinal strength of a damaged box girder, in Guedes Soares, C. \& Shenoi R. A., (Eds.). Analysis and Design of Marine Structures. London, Taylor \& Francis Group, 435-441

Yamamoto N, Ikegami K (1998) A study on the degradation of coating and corrosion of ship's hull based on the probabilistic approach, Journal of Offshore Mechanics and Arctic Engineering ASME 120(3):121-128

Yamamoto N, Yao T (2001) Hull girder strength of a tanker under longitudinal bending considering strength diminution due to corrosion, structural safety and reliability. In: Proceedings of the 8th international conference (ICOSSAR2001)

Yang B, Guedes Soares C, Wang DY (2019) Dynamic ultimate compressive strength of simply supported rectangular plates under impact loading. Mar Struct 66:258-271

Yang B, Guedes Soares C, Wang DY (2018a) An empirical formulation for predicting the dynamic ultimate strength of rectangular plates under in-plane compressive loading. Int J Mech Sci 141:213-222

Yang B, Wu JM, Guedes Soares C, Wang DY (2018b) Dynamic ultimate strength of outer bottom stiffened plates under in-plane compression and lateral pressure. Ocean Engineering. 157:44-53

Yang H, Zhang Q, Tu S, Wang Y, Huang Y (2016) A study on timevariant corrosion model for immersed steel plate elements considering the effect of mechanical stress. Ocean Eng 1251:134-146

Yang Y, Huang R, He Z (2020) Experimental study of the uniaxial compressive behaviour of DH36 steel plates with mechanically induced pits. Ocean Eng 200(107058):107058

Yao T, Fujikubo M, Lijima K, Pei Z (2009) Total system including capacity calculation applying ISUM/FEM and loads calculation for progressive collapse analysis of ship's hull girder in longitudinal bending. International Society of Offshore and Polar Engineers

Yao T, Nikolov PI (1990) Buckling/plastic collapse of plates under cyclic loading. J Soc Naval Archit Japan 1990(168):449-462

Yao Y, Yang Y, He Z, Wang Y (2018) Experimental study on generalized constitutive model of hull structural plate with multi-parameter pitting corrosion. Ocean Eng 170:407-415

Zayed A, Garbatov Y, Guedes Soares C (2007a) Corrosion modelling of single-hull crude oil tanker subjected to multiple deterioration environments. In: Proceedings of the 26th International Conference on Offshore Mechanics and Arctic Engineering, San Diego, USA, ASME, New York, paper OMAE2007-29741

Zayed A, Garbatov Y, Guedes Soares C (2007b) Factors affecting the non-destructive inspection of marine structures, in: Guedes Soares C., Das, P. K. (eds) Advancements in Marine Structures. advancements in marine structures. Taylor \& Francis Group, London, pp $565-576$ 
Zayed A, Garbatov Y, Guedes Soares C (2013) Reliability of ship hulls subjected to corrosion and maintenance. Struct Saf 43:1-11

Zayed A, Garbatov Y, Guedes Soares C (2018) Corrosion degradation of ship hull steel plates accounting for local environmental conditions. Ocean Eng 163:299-306

Zhang Y, Huang Y, Meng F (2017a) Ultimate strength of hull structural stiffened plate with pitting corrosion damage under uniaxial compression. Mar Struct 56:117-136
Zhang Y, Huang Y, Wei Y (2017b) Ultimate strength experiment of hull structural plate with pitting corrosion damage under uniaxial compression. Ocean Eng 130:103-114

Zhang Y, Huang Y, Zhang Q, Liu G (2016) Ultimate strength of hull structural plate with pitting corrosion danification under combined loading. Ocean Eng 116:273-285

Zhao Z, Zhang H, Xian L, Liu H (2020) Tensile strength of Q345 steel with random pitting corrosion based on numerical analysis. ThinWalled Struct 148(106579):106579 